NBER WORKING PAPER SERIES

\title{
ARE SOME DEGREES WORTH MORE THAN OTHERS? EVIDENCE FROM COLLEGE ADMISSION CUTOFFS IN CHILE
}

\author{
Justine S. Hastings \\ Christopher A. Neilson \\ Seth D. Zimmerman \\ Working Paper 19241 \\ http://www.nber.org/papers/w19241
}

\author{
NATIONAL BUREAU OF ECONOMIC RESEARCH \\ 1050 Massachusetts Avenue \\ Cambridge, MA 02138 \\ July 2013
}

We thank Noele Aabye, Phillip Ross, Unika Shrestha and Lindsey Wilson for outstanding research assistance. We thank Nadia Vasquez, Pablo Maino, Valeria Maino, and Jatin Patel for assistance with locating, collecting and digitizing data records. J-PAL Latin America and in particular Elizabeth Coble provided excellent field assistance. We thank Ivan Silva of DEMRE for help locating and accessing data records. We thank the excellent leadership and staff at the Chilean Ministry of Education for their invaluable support of these projects including Harald Beyer, Fernando Rojas, Loreto Cox Alcaíno, Andrés Barrios, Fernando Claro, Francisco Lagos, Lorena Silva, Anely Ramirez, and Rodrigo Rolando. We also thank the outstanding leadership and staff at Servicio de Impuestos Internos for their invaluable assistance. We thank Joseph Altonji, Peter Arcidiacono, Ken Chay, Raj Chetty, Matthew Gentzkow, Nathaniel Hilger, Caroline Hoxby, Wojciech Kopczuk, Thomas Lemieux, Costas Meghir, Emily Oster, Jonah Rockoff, Jesse Shapiro, Glen Weyl and participants at University of Chicago, Harvard, Princeton, the U.S. Consumer Financial Protection Bureau, the Federal Reserve Bank of New York, the NBER Public Economics and Education Economics program meetings, and Yale for helpful comments and suggestions. This project was funded by Brown University, the Population Studies and Training Center at Brown, and NIA grant P30AG012810. The views expressed herein are those of the authors and do not necessarily reflect the views of the National Bureau of Economic Research. Online Appendix available at: http://www.justinehastings.com/images/downloads/HNZ_Chile_Appendix_2013a.pdf.

NBER working papers are circulated for discussion and comment purposes. They have not been peerreviewed or been subject to the review by the NBER Board of Directors that accompanies official NBER publications.

(C) 2013 by Justine S. Hastings, Christopher A. Neilson, and Seth D. Zimmerman. All rights reserved. Short sections of text, not to exceed two paragraphs, may be quoted without explicit permission provided that full credit, including $(\mathcal{C}$ notice, is given to the source. 
Are Some Degrees Worth More than Others? Evidence from college admission cutoffs in Chile

Justine S. Hastings, Christopher A. Neilson, and Seth D. Zimmerman

NBER Working Paper No. 19241

July 2013, Revised September 2014

JEL No. H52,I23,I24,I25,I28,J24,J31

\begin{abstract}
Understanding how returns to higher education vary across degree programs is critical for effective higher education policy. Yet there is little evidence as to whether all degrees improve labor market outcomes, and whether they do so for students from different types of backgrounds. We combine administrative and archival data from Chile with score-based admissions rules at more than 1,100 degree programs to study how the long-run earnings effects of college admission depend on selectivity, field of study, and student characteristics. Our data link admissions outcomes for 30 cohorts of college applicants to administrative records of labor market outcomes up to 30 years post-application. We estimate regression discontinuity specifications for each degree, and describe how threshold-crossing effects vary by degree type. In addition, we use variation in admissions outcomes driven by threshold-crossing to estimate a simple model that maps our discontinuity estimates into causal effects of admission by degree. Observed choice and survey data indicate that the assumptions underlying this model are consistent with student behavior. We find that returns are heterogeneous, with large, positive returns to highly selective degrees and degrees in health, science, and social science fields. Returns to selectivity do not vary by student socioeconomic status. Our findings suggest a role for policies that guide students toward higher-return degrees, such as targeted loans and better college preparation for students from low-income backgrounds.
\end{abstract}

Justine S. Hastings

Brown University

Department of Economics

64 Waterman Street

Providence, RI 02912

and NBER

justine_hastings@brown.edu

Christopher A. Neilson

Yale University

Department of Economics

37 Hillhouse Ave.

New Haven, CT 06511

christopher.neilson@yale.edu
Seth D. Zimmerman

Industrial Relations Section

Princeton University

Firestone Library

1 Washington Road

Princeton, NJ 08544

seth.zimmerman@chicagobooth.edu 


\section{Introduction}

The college wage premium in the U.S. has risen dramatically since the early 1980s. ${ }^{1}$ In response, state and local governments seeking to broaden access to higher education have expanded student loan programs. ${ }^{2}$ Many students have taken advantage of these expansions: college-going rates rose 52\% between 1990 and 2010, while federal loan debt per borrower increased by 250\%. ${ }^{3}$ However, default rates on federal student loans also rose through the 2000s, and the early 2010s saw large protests over high debt and ex post regret of higher education investment. Similar movements have emerged recently in other developed countries, such as England and Chile, presenting a puzzle for policy makers. ${ }^{4}$ If the returns to college are high, why are students having trouble paying back their loans?

One possibility is that labor market returns vary widely depending on where students go to school, what they study, and their academic and social backgrounds. Though current policy proposals consider regulating loan or grant funding for degrees based on perceived payoffs in the labor market, little evidence exists to guide such interventions. ${ }^{5}$ In this paper, we use score-based cutoffs for admission to more than 1,100 different college degree programs to obtain causal estimates of the earnings gains associated with admission to each degree. We evaluate earnings outcomes using tax records up to thirty years post-application, and use our estimates to describe how earnings gains vary by program selectivity, field of study, and student socioeconomic background. In doing so, we provide new evidence to inform key higher-education policy debates.

We accomplish this by exploiting unique and extensive data from Chile, a middle-income OECD member country. Like the U.S., Chile has experienced large gains in enrollment (94\%) and loan debt per student (over 100\%) in the past 20 years. ${ }^{6}$ Unlike the U.S., but like many countries in Europe, Asia, and Latin America, university admissions outcomes in Chile are determined only by indices of grades and test scores. The admissions system generates sharp cutoffs in admissions outcomes at nearly all university degree programs, which allows for causal identification of admissions effects at many different margins

\footnotetext{
${ }^{1}$ See Cutler \& Katz (1992); Karoly \& Burtless (1995); Bound \& Johnson (1992); Katz \& Murphy (1992); Murphy \& Welch (1993); Juhn, Murphy \& Pierce (1993); Goldin \& Katz (2007); Autor, Katz \& Kearney (2008).

${ }^{2}$ Examples of increased subsidies in the U.S. include the U.S. Student Loan Reform Act of 1993 and the College Cost Reduction and Access Act (CRAA) in 2007.

${ }^{3}$ Enrollment: U.S. Department of Education, NCES Digest 2011, Table 198. Statistics exclude institutions offering only career and technical programs. Loans: U.S. Department of Education, 2012. Deflated using CPI-U. Link:

http://www2.ed.gov/about/overview/budget/budget13/justifications/r-loansoverview.pdf.

${ }^{4}$ For descriptions of protests, see e.g. http://www.nbcnews.com/id/45040659/ns/us news-life/t/another-idea-student-loan-debtmake-it-go-away/\#.UYfDa8pbMyQ, http://www.economist.com/node/21552566, and http://www.theguardian.com/education/2010/nov/10/student-protest-fees-violent.

${ }^{5}$ For example, the Gainful Employment Act sought to limit federal subsidies to institutions with low loan repayment rates. See http://www.ed.gov/news/press-releases/obama-administration-takes-action-protect-americans-predatory-poor-performing-ca. ${ }^{6}$ See Rolando et al. (2010). In Chile the largest loan expansion was the 2005 Crédito con Garantia Estatal (Loan with State Guarantee, commonly called CAE for Crédito Aval del Estado). See Crédito de la Ley 20.027 para Financiamiento de Estudios de Educación Superior.
} 
simultaneously. Also unlike the U.S., it is possible to systematically link records for the population of Chilean college applicants to earnings outcomes. Our data link college application records for students applying to college between 1982 and 2011 to administrative tax return data for the years 2005 through 2012. We collected these data from a combination of administrative and archival sources, linking across datasets using unique national identification numbers. ${ }^{7}$

Our research design takes advantage of several features of the Chilean college application system. Chilean students apply to a career (major) and university simultaneously (e.g. Civil Engineering at the University of Chile) as part of a centralized, score-based application process. We refer to an institutioncareer combination as a degree. Students rank up to eight degree choices in order of preference. The applicants are then scored by universities using a combination of entrance exam scores and GPAs.

Students are admitted to at most one of their choices based on their preferences and their score using an algorithm similar to that used in the U.S. medical residency match. This process creates regression discontinuities around a cutoff score that is unknown ex ante (Azevedo and Leshno 2014). We compare average earnings for students just above versus just below these cutoffs.

Our analysis has two components. In the first, we estimate the effects of crossing the thresholds for admission to each of 1,103 degree programs on long-run earnings outcomes. We then compare the distributions of these effects by the selectivity and field of study of the target degree program, as well as by student demographics. In the second, we develop a simple model of college choice and earnings, and estimate the earnings equation using variation in admissions outcomes generated by threshold-crossing.

These two components complement one another. The first allows us to construct estimates of the earnings gains associated with admission to different kinds of degree programs for marginal applicants. These estimates are of interest for a variety of policy questions, such as the choice to marginally expand or contract a particular degree program. The second allows us to estimate earnings effects for each degree program relative to a common outside option under the assumption that selection into degree programs is uncorrelated with unobservable determinants of degree-specific comparative advantage. This assumption appears consistent with empirical evidence from observed choices and survey data on the factors driving student choices. Within this framework, we can examine issues such as how quickly earnings effects rise with degree selectivity, how much earnings returns vary across fields of study, and how socioeconomic status interacts with degree returns in high- versus low-selectivity degrees.

Our threshold-crossing estimates show that admissions to selective degrees and degrees with a focus on health, social science, or science/technology yield positive and significant earnings gains. On

\footnotetext{
${ }^{7}$ We were able to compile these data and link them to tax records with the permission and political and logistical support of the Ministry of Education in Chile (MINEDUC) and the Office of the President. The data collection was permitted and supported with the purpose of providing research evidence to inform important reforms to higher education policy in response to widespread protests over student loan repayment.
} 
average, crossing the threshold for admission to a targeted degree program raises earnings by an amount equal to $4.5 \%$ of the average sample earnings. Threshold-crossing estimates increase in degree selectivity, from $2.0 \%$ for degrees with cutoffs in the lowest selectivity quartile to $9.1 \%$ in degrees from the highest quartile. Effects differ substantially by field of study, with large effects for degrees in health $(10.8 \%$ of average earnings) and social science (8.2\%). Threshold-crossing effects for art, humanities, and education degrees are small or negative and do not differ significantly from zero.

Threshold crossing estimates reflect the difference between earnings outcomes at the target degree and the mix of alternate degrees selected by just-rejected students. Because marginal applicants to high-earning target degrees often have high-earning alternate degrees, degree effects evaluated relative to the common outside option are larger and rise more quickly with selectivity than threshold-crossing estimates, from $4.7 \%$ of average earnings in the bottom selectivity quartile to $24.2 \%$ in the top quartile. Earnings relative to the outside option are highest for health degrees, social science degrees, law degrees, and science/technology degrees $(25.6 \%, 16.1 \%, 15.1 \%$, and $11.9 \%$ of average earnings, respectively). These gains do not appear to be fully captured by higher tuition.

Looking at heterogeneity in earnings effects by demographic groups, we find similar effects across selectivity groups for students from low- and high-SES backgrounds. However, effects differ in intuitive ways by field of study. Students from high-SES backgrounds realize large earnings gains (30.7\%) from attending high-selectivity business degrees, where soft skills, social or familial networks, and networking skills may be more valuable, while students from low-SES backgrounds do not realize any gains at all. In contrast, students from high- and low-SES backgrounds benefit similarly from admission to selective health, science and technology, law, and social-science degrees.

This paper contributes to several literatures. This is the first analysis to use many regression discontinuities to trace out the labor market returns to the marginal admission across the selectivity distribution. A number of previous authors use regression discontinuity designs to measure the labor market gains associated with admission to particular colleges or secondary schools (Hoekstra 2009; Ockert 2010; Ozier 2013; Saavedra 2009; Zimmerman 2014).

This is also the first paper to consider the way that marginal returns vary by field of study, and, within field of study, by selectivity. In contrast to papers that focus on effects at a single admissions margin, our findings can be used by policymakers considering tradeoffs in the allocation of spots to different degree programs. To the best of our knowledge, we provide the first quasi-experimental evidence that field of study plays a causal role in determining labor market outcomes; earnings gaps across fields are not just the result of selection. Our results add to the prior literature which either describes earnings gaps by field of study or corrects for selection into degree programs by modeling and 
estimating the student choice problem (Altonji et al. 2012; Arcidiacono 2004; Beffy, Fougere, and Maurel 2012).

Our results suggest that marginal expansions of high-selectivity programs are more likely to allow students to make investments with high private returns than marginal expansions of low-selectivity programs. Furthermore, earnings gains from admission to high-selectivity degrees are large for both highand low-SES students. This suggests that educational policies aimed at increasing the number of low-SES students qualifying for ${ }^{8}$ and choosing degrees at selective higher-education institutions could provide greater economic opportunity than programs that increase the number of low-SES students attending less selective degrees (Hoxby and Avery 2012; Hoxby and Turner 2013; Deming et al. 2014).

The strategy we develop for estimating the effects of interest and assessing the plausibility of the underlying assumptions may be useful in future work as data encompassing multiple admissions thresholds becomes more common (Goodman et al. 2014; Saavedra 2009; Urquiola and Pop-Eleches 2013). Our model helps identify the labor market effects of different educational programs relative to the common outside option of not attending a selective degree program using only variation in admissions outcomes generated by threshold-crossing. In doing so, we link the literature on regression discontinuity estimates of earnings effects to a broader strand of research that uses other methods to assess heterogeneity in earnings returns across selectivity (Dale and Krueger 2002, 2011; Black and Smith 2004, 2006), institution type (Deming, Katz, and Goldin 2012; Kane and Rouse 1995), and field of study.

Finally, our findings speak to key policy questions. First, they suggest sizeable market frictions in the supply of and/or demand for high-return degrees. Marginally increasing offerings in particular fields could raise aggregate earnings, suggesting constraints on supply (Bound and Turner, 2007). On the other hand, while excess demand for degrees with zero to negative earnings returns may be driven by nonpecuniary factors, recent empirical evidence suggests that students may make uninformed or short-sighted college and career choices (Arcidiacono et al. 2010; Jensen, 2010; Scott-Clayton 2012; Hastings et al. 2014; Hastings, Neilson and Zimmerman 2014; Jacob, McCall and Stange, 2013; Wiswall and Zafar 2013). Information aggregation may be a public good, suggesting a role for government to facilitate informed demand and responsive supply (Beyer et al. 2014; Lavecchia, Liu and Oreopoulos, 2014).

\footnotetext{
${ }^{8}$ For example, by adopting early childhood, primary and secondary education policies that raise achievement among minority and low-income students.
} 


\section{College Applications in Chile}

\subsection{Chilean Postsecondary Education: CRUCH Applications and Admissions}

The centralized university admissions system in Chile is run by the Council of Rectors of the Universities of Chile (CRUCH). CRUCH member institutions include all universities that existed in Chile prior to 1981. CRUCH institutions are all not-for-profit, but can be public, private, or private-parochial. CRUCH universities span a wide range of selectivity levels. The two most selective Universities are Universidad de Chile (a public university) and Pontificia Universidad Católica de Chile (a private Catholic university), both of which send top students to some of the most selective graduate programs in the world. Most degrees at these institutions are licenciatura (licensure) degrees, which take 5 years to complete on time. Overall, for those entering a CRUCH degree between 2000 and 2004, 63.2\% graduated at their enrolled institution within $150 \%$ of expected degree completion time. ${ }^{9}$ The corresponding statistic for all fouryear, Title IV-eligible institutions in the U.S. is $57.5 \%{ }^{10}$

Students applying to CRUCH institutions must take a standardized test for admission. This test was called the PAA (Prueba de Aptitud Académica, or Academic Aptitude Test) until 2002 (taken for the 2003 college entering year), and the PSU (Prueba de Selección Universitaria, or University Selection Test) after 2002. It is constructed and administered by the central testing authority, DEMRE (for Departamento de Evaluación, Medición y Registro Educacional, or the Department of Educational Evaluation, Measurement and Registration), which operates under the authority of the CRUCH. All entrance exam takers complete exams in mathematics and language, and many students also take optional tests in other subjects. Scores are scaled to a distribution with range 150 to 850 and a mean and median of 500. Entrance exam scores, along with high-school GPA, are the primary components of the composite scores used for postsecondary admissions, scholarships, and student loan eligibility.

After taking the entrance exam and receiving their scores, students choose where to apply and submit their application to CRUCH. As in many other postsecondary education systems (though typically not the U.S.), a choice indicates both an institution and a career. We will refer to an institution-career combination as a degree or degree program. Students submit one application with up to eight ranked degree choices. ${ }^{11}$ Once students apply, their entrance exam scores and GPAs are used by CRUCH members to assign a score for each student for each degree. Students selecting a particular degree are

\footnotetext{
${ }^{9}$ Author's calculations using Proyecto 3E database.

${ }^{10}$ U.S. Department of Education, NCES Digest 2011, Table 345. The value is the average of the 2000-2004 starting cohorts.

${ }^{11}$ Other systems that use or have used centralized applications include the state university system in California (see http://admission.universityofcalifornia.edu/how-to-apply/index.html and

https://secure.csumentor.edu/support/pdfs/express app.pdf), German universities (Braun et al. 2010), Swedish universities (Ockert 2010), and Chinese universities (Chen and Kesten 2013).
} 
admitted in order of their score until all slots are filled or demand is satiated. Roughly $90 \%$ of applications are submitted to degrees with excess demand.

Students are offered at most one admission slot: they are admitted to their most preferred degree for which they achieved a sufficiently high score. Online Appendix, Section II describes the CRUCH scoring and admission algorithm in detail. Students have an incentive to rank order their choices correctly (they should not list a less-preferred choice over a more-preferred choice), though they may incorporate overall probability of admission in deciding which options to list (as they are capped at eight options). While students apply with some knowledge of where they might be admitted (applications display "reach" and "safety" schools), cutoff scores vary unpredictably from year to year as shocks to demand for various degrees ripple through the system. ${ }^{12}$ These sharp and unpredictable cutoffs generate exogenous variation in admissions outcomes.

\subsection{Outside-of CRUCH Options: 1980 to Present}

In the 1980s, at the beginning of our sample period, CRUCH universities accounted for nearly all university enrollment in Chile. Students who were not admitted through the centralized application system were forced to enroll in non-selective technical or professional schools if they wished to continue their education. Over time, a number of newer universities operating outside the CRUCH system entered the higher education market. These newer universities are predominantly private and typically serve lower-scoring students. They do not participate in the centralized admissions process. During the 1980s, CRUCH universities accounted for more than $95 \%$ of university graduates. By 2000 , however, near the end of our sample period, the CRUCH share had fallen to $67 \% .{ }^{13}$ Online Appendix Section I discusses how outside postsecondary options in Chile have changed between 1983 and 2009. ${ }^{14}$ Solis (2013) and Beyer et al. (2014) discuss the role that student loan programs played in the education market expansion and tuition inflation in Chile from 2006 to 2013.

One goal of this paper is to measure the earnings gains associated with admission to selective CRUCH degree programs relative to the common outside option of not attending a selective CRUCH program. To better understand how changes in this outside option over time may affect our estimates, we will present threshold-crossing and model estimates based on only the 1982-1989 application cohorts alongside our main estimates for the full set of 1982-2006 applicants. For these students, the outside option for higher education was a technical or professional degree rather than a non-CRUCH university. Estimates for older cohorts have a clearer outside option to aid interpretation, but span fewer degree

\footnotetext{
${ }^{12}$ Admission cutoff scores vary significantly within a degree over time. The average standard deviation in cutoff score for a degree in our marginal sample is 19.4 points, making the actual cutoff in a particular year unpredictable.

${ }^{13}$ Rolando et al. (2010), Mineduc report on aggregate trends in postsecondary education.

${ }^{14}$ Online Appendix is here: http://www.justinehastings.com/images/downloads/HNZ_Chile_Appendix_2013a.pdf.
} 
programs. We find similar patterns across degree characteristics in the older-cohort and all-cohort samples.

While we do not have universal enrollment outside of CRUCH in early sample years (see data description in Section 3), we do know that, by 2000, 15.0\% of applicants who were not admitted to any CRUCH option enrolled in a private university that year, ${ }^{15}$ while $5.2 \%$ enrolled in a technical or professional degree program and 79.6\% did not enroll anywhere. By two years after initial application, these numbers were $34.8 \%, 12.6 \%$, and $52.5 \%$ respectively (see enrollment tables in Online Appendix Section I). ${ }^{16}$ Extrapolating back using overall market share of CRUCH vs. Private-non-CRUCH vs. technical/professional enrollment, about 16\% of rejected applicants in 1990 (graduating in 1995 or 1996) would have enrolled in a private university within two years, with the large majority enrolling in no postsecondary education. Thus the non-CRUCH options for rejected applicants in the 1980s and 1990s can be thought of as consisting of a) eventual (within 2 years) CRUCH enrollment (about $26 \%$ of students), b) eventual private school enrollment (about 12.5\% of students), c) eventual technical or professional enrollment (about $37.5 \%$ of students), or d) non-enrollment (about $24 \%$ of students). ${ }^{17}$

\section{Data}

\subsection{Administrative records on college applicants}

We construct our analysis dataset from a variety of administrative and archival sources. We summarize the process here, with additional detail available in Online Appendix Section III. We digitized test score, admissions, and waitlist results for all CRUCH schools and careers between 1982 and 2000 from original paper copies. We then digitized data on PAA/PSU scores from 1982-2000 from hard copy records at the testing authority and matched these by individual identifiers to the admissions data. These records also include information on gender and high school identification numbers.

Using high school identifiers, we construct measures of student socioeconomic status. The Chilean Ministry of Education (Mineduc) categorizes high schools by the poverty-level of their studentbody. There are five categories, A through E, with A being the highest-poverty and E being the lowest-

\footnotetext{
${ }^{15}$ From row 1 of Table A.I.III, 71.1\% of applicants do not enroll in a CRUCH option (1 - 0.083 - 0.206). Of those 71.1\%, 15.0\% $(0.107 / 0.711)$ enroll in a private non-CRUCH university.

${ }^{16}$ The large majority of students applying to postsecondary education in Chile are either just graduating high school, or graduated high school within the past two years.

${ }^{17}$ Extrapolated based on $24 \%$ of those not admitted in 2000 did not matriculate anywhere within 2 years (see Table A.I.III.) and $26 \%$ of rejected applicants from 1985-1999 were admitted to a CRUCH option within 2 years. The remaining 50\% were extrapolated based on the fact that from 1985-1999, $25 \%$ of non-CRUCH enrollment was at private universities and $75 \%$ was at IPs (Institutos Profesionales or Professional Institutes) or CFTs (Centros de Formación Técnica or Technical Formation Centers.) See Figure A.I.II.
} 
poverty. While poverty ratings are only available during the 2000 s, they are persistent over time. We classify students as low-SES if they graduated from a high school that received an A, B, or C ranking in 2000 . $^{18}$ Though some high schools from the 1980s and 1990s do not appear in 2000 data, most do. We are able to match $84 \%$ of marginal applicants overall, including $79 \%$ of pre-1990 applicants.

Beginning in 2001, we have electronic records of the full college application process. These records include high school graduation records with gender, GPA and high school of graduation. We link these records to digital records of applications to CRUCH schools. These records include all listed choices, admissions and waitlist decisions, and demographic information such as gender and family income. Additionally, we link these records to entrance exam scores. For the years 2000 through 2011, we have data on college attendance and graduation from almost all postsecondary degree-granting institutions in Chile. We worked with Mineduc to compile these data. Combined, these data give us a panel of college applicants and graduates from 1982 through 2011 - 30 cohorts of students.

We match these data to individual tax records at the Chilean tax authority in compliance with Chilean privacy laws. ${ }^{19}$ Over $99 \%$ of individuals in our data have matches in the tax records. The tax records are available for tax years 2005 to 2012, and include all labor earnings. Prior to 2005, administrative earnings micro-data are not available for a significant portion of wage earners. Online Appendix Section IV describes the tax records in Chile in detail and explains how we construct labor earnings. All values are reported in 2011 pesos.

Our earnings analysis includes zero earnings values. We include zero earnings to capture returns due to changes in the extensive labor supply margin as well as increases in productivity and movement along the intensive labor supply margin. In Online Appendix Section VII we present regression discontinuity estimates of participation effects. These effects are quite small: our results are driven largely by changes in earnings conditional on some work. We top-code the highest one percent of earnings, conditional on cohort and experience, to reduce the impact of earnings outliers in our analysis. Specifically, we divide earnings observations into cells based on a full interaction between application cohort and years since application. We then set observations in the top one percent of the distribution in each bin to the $99^{\text {th }}$ percentile value for the bin. Our results are robust to moving this threshold up to the $99.5^{\text {th }}$ percentile or down to the $98^{\text {th }}$ percentile. We present regression discontinuity estimates for these alternate top-code values in Online Appendix Section VII.

\footnotetext{
${ }^{18}$ The poverty ratings are highly correlated with family income. We measured family income in tax data using parental identifiers linked to student identifiers. Our family income measures are highly correlated with the Mineduc poverty rating. In addition, there are no municipal (public, non-voucher) schools with poverty-rating E, and no private schools with poverty-rating A. ${ }^{19}$ This disclosure is required by the Chilean government. SOURCE: Information contained herein comes from taxpayers' records obtained by the Chilean Internal Revenue Service (Servicio de Impuestos Internos), which was collected for tax purposes. Let the record state that the Internal Revenue Service assumes no responsibility or guarantee of any kind from the use or application made of the aforementioned information, especially in regard to the accuracy, validity or integrity.
} 


\subsection{Administrative records on postsecondary institutions and degrees}

We focus on two types of degree program characteristics. The first is field of study. Career data come with administrative categorizations based on CINE-UNESCO (UNESCO Normalized International Classification of Education) standards. There are ten categories: agriculture, art and architecture, basic science, business administration, education, health, humanities, law, social science, and technology. The basic science and agriculture classifications contain relatively few degree programs, so we group them with technology degrees into a broader science/technology category based on similar program content. This leaves us with eight fields of study. Online Appendix Section V details these field categorizations and provides examples of specific careers in different field and selectivity categories. ${ }^{20}$ The second is selectivity. We categorize degrees into selectivity tiers based on quartiles of average math and language scores for admitted students. Two degrees within the same institution can fall into different selectivity categories; some institutions may specialize in certain fields and not in others.

Tables A.I.I. and A.I.II in the Online Appendix present descriptive statistics on CRUCH institutions and CRUCH applications, respectively. While selectivity is defined at the degree level, some institutions have more selective degrees across all fields than others. Pontificia Universidad Católica is the most selective private institution and Universidad de Chile is the most selective public institution. However, both offer a wide range of degrees, not all of which are of above-median selectivity. Many universities offer some selective options, with the fraction of selective degrees increasing with overall university selectivity. Some universities focus on particular fields (e.g. education at U. Metro. en Ciencias de la Educación or U. de la Serena). Students applying to CRUCH over the years 2001-2011 (the years for which data on preference rankings is available) on average list only four or five out of eight possible choices. Students list an average of three to four different careers in close to two different CINEUNESCO areas, at 2.5 different universities and crossing 1.6 to 1.7 selectivity tiers. On average, students who are admitted somewhere are selected to a little less than their second choice. About $68 \%$ of students are admitted to at least one choice, and of those, $70-75 \%$ matriculate at that choice.

Combining each of the data sets above, we construct an estimation sample of applications that fall within 25 points on either side of the admission cutoff to a degree-year for which there was excess demand. We define degree-year combinations as having excess demand if we observe a minimum of 18 applications in the five points below the cutoff score. ${ }^{21}$ These are the students on the margin of admission.

Table I compares characteristics of the full sample with our estimation sample and the sample of students near the score cutoff for admission to each institution-career in each application year. Column 1

\footnotetext{
${ }^{20} \mathrm{We}$ also present regression discontinuity estimates disaggregated by the original ten fields.

${ }^{21}$ Online Appendix Section VII presents regression discontinuity and model estimates for wider and narrower bandwidths and more and less inclusive definitions of excess demand.
} 
shows summary statistics for all applications. Column 2 shows summary statistics for applications in the estimation sample. Column 3 shows summary statistics for applications in the estimation sample for which we have full data on field of study and selectivity for the target degree. We are missing this data for approximately three percent of applications. ${ }^{22}$ On average, students in our marginal sample have higher entrance exam scores, are more likely to be applying to a business degree, and less likely to be applying to an education degree. They are more likely to be applying to high-selectivity degrees, since low selectivity degrees may not have marginal students in some years.

Marginal applicants are slightly more likely to be male, and significantly more likely to come from high SES high schools. Average labor earnings between 2005 and 2012 (in constant 2011 pesos) for our marginal group are about $18 \%$ higher than those for the total applicant population. Converting to U.S. dollars using OECD Purchasing Power Parity data for 2011 indicates that mean earnings for students in the applicant population were roughly $\$ 25,400$, compared to $\$ 29,000$ for students in the marginal sample. ${ }^{23}$ To facilitate interpretation, we will divide estimated effects by mean full sample earnings in much of what follows. We observe positive earnings for $82.3 \%$ of students in the full sample and $83.2 \%$ of students in the marginal sample.

We observe students applying to between 450 and 900 different CRUCH degrees per year over the period 1982-2006. Overall, we observe 1,923 separate CRUCH degree programs, with degree identifiers missing for $1.3 \%$ of applications. We observe marginal students subject to binding cutoffs in 1,103 of these degree programs, accounting for $88.2 \%$ of all applications. The remaining degrees for which there are no regression discontinuities are defined as part of the outside option, which we interpret as including the option to attend a non-selective CRUCH degree program. We also examine a more inclusive definition of binding admissions cutoffs as a robustness check. This alternative definition includes 1,188 degrees and $91.3 \%$ of all applications. Our findings are robust to this change. See Online Appendix Section I for a more detailed discussion of the outside option and Online Appendix Section VII alternate estimates of earnings models.

\section{Model and Empirical Framework}

\footnotetext{
${ }^{22}$ We include degrees with missing data in our model analysis, treating "missing data" as a degree characteristic.

${ }^{23}$ Exchange rate taken from OECD data on Purchasing Power Parities for actual individual consumption. Exchange rate of Chilean Pesos to U.S. Dollars was 334 to 1 in 2011. http://stats.oecd.org/Index.aspx?DataSetCode=SNA_Table4, accessed September 9, 2014.
} 


\subsection{Estimating threshold-crossing effects}

We estimate the effect of admission to each degree program $p$ using standard regression discontinuity specifications of the form

$$
Y_{i p}=f_{p}\left(d_{i p}\right)+\Delta_{p} Z_{i p}+\varepsilon_{i p}
$$

where $Y_{i p}$ is average earnings over outcome years 2005-2012 for individual $i$ who applies to degree $p{ }^{24}$ $d_{i p}$ is the difference between the admissions score assigned to $i$ 's application to program $p$ and the cutoff score for admission to that program in the year $i$ applies, $f_{p}\left(d_{i p}\right)$ is a smooth function of the score difference (which can change on either side of the cutoff), $Z_{i p}=1\left(d_{i p} \geq 0\right)$ is an indicator variable equal to one if $i$ 's application to degree $p$ is above the cutoff score (so $i$ is accepted to program $p$ ), and $\varepsilon_{i p}$ is an error term. We estimate equation (1) separately for every degree in the system using data within a narrow score window around the cutoff point.

\subsection{A model of earnings and degree choice}

Estimates of $\Delta_{p}$ capture the impact of crossing the admissions threshold to degree $p$ for students near the threshold and are useful for answering certain policy questions. However, they do not allow for straightforward comparisons of earnings effects across different degree programs $p$. To see this, consider a simple model of earnings determination. Write average annual earnings for individual $i$ admitted to degree $p$ as

$$
Y_{i p}=\mu_{i}+\theta_{p}+\phi_{i p}+\omega_{i p}
$$

where $Y_{i p}$ is average annual earnings, $\theta_{p}$ is the mean earnings gain from admission to degree $p$ in the population (relative to not being admitted to any degree, which is normalized to zero), $\mu_{i}$ is an individual-specific component of earnings that accrues regardless of admissions outcome. $\phi_{i p}$ is an individual-specific return to degree $p$ known to individual $i$ at the time of selecting a degree, which can include both observable and unobservable (to the econometrician) factors and is normalized to have a

\footnotetext{
${ }^{24}$ These averages exclude earnings observations from fewer than six years after college application.
} 
mean of zero. $\omega_{i p}$ is a mean-zero individual-specific return from attending degree $p$ realized after attending $p . \omega_{i p}$ does not play a role in degree choice. ${ }^{25}$

Consider the group of students applying for admission to degree $p$. Those just below the threshold will be admitted to a mixture of other degrees $q$. Using equation (2), the average effect of crossing the threshold for admission at degree $p$ on earnings is given by:

$$
E\left(\Delta_{p}\right)=\left(\theta_{p}-\sum_{q} \pi_{p q} \theta_{q}\right)+\left(\sum_{q} \pi_{p q} E\left(\phi_{i p}-\phi_{i q} \mid i \in I_{p q}\right)\right)
$$

where $\pi_{p q}$ is the probability that individuals just below the threshold of admission to degree $p$ will be admitted to degree $q$, and $I_{p q}$ is the set of students on the margin of admission to degree $p$ whose belowthreshold alternate outcome is degree $q$. The first term is the probability-weighted difference in mean earnings gains from admission to degree $p$ versus any other degree in the system. The second term is a probability-weighted average of individual-specific gains from admission to degree $p$ relative to degree $q$ given that individual $i$ was on the margin of admission to degree $p$ and would have attended degree $q$ had he been rejected from $p$.

Threshold-crossing effects depend on a mix of earnings effects and admissions probabilities. A degree can have a high $\Delta_{p}$ because it has a high $\theta_{p}$, because rejected applicants to $p$ are more likely to be admitted to degrees with low values of $\theta_{q}$, or because applicants to $p$ have large individual-specific comparative advantages in $p$ relative to alternatives $q$. The $\Delta_{p}$ do not map to population average treatment effects $\theta_{p}$ or treatment-on-the-treated effects $\theta_{p}+E\left[\phi_{i p} \mid\right.$ choose $\left.\mathrm{p}\right]$ in a straightforward way. ${ }^{26}$

We exploit the fact that we have access to discontinuity estimates for the population of degrees to recover estimates of treatment effects from cross-threshold changes in earnings and admissions outcomes. To do so requires further assumptions on either the $\phi_{i p}$ or the process by which students choose degrees. One approach is to jointly model and estimate choice of degree and earnings outcomes, assuming fullyinformed and forward-looking degree choice driven by correct beliefs about earnings distributions over a full choice set, choice mechanisms, and assignment mechanisms. This approach would also require

\footnotetext{
${ }^{25}$ The $\phi_{i p}$ allow for essential heterogeneity in the sense of Heckman et al. (2006). For simplicity, this model abstracts from possible differences in the growth of earnings for students admitted to different degree programs.

${ }^{26}$ To solve this same problem in the school choice setting, researchers often impose that impact of school admission on test scores is a function of measureable school value-added, and use a probability-weighted value-added of home schools to measure gains in school quality from crossing a threshold or winning a lottery. See for example Deming et al (2014). Here we do not have a-priori measures of earnings gains by field and degree of study, rather the goal is to estimate them.
} 
functional form assumptions on utility from degree choice. We would jointly estimate returns and preference parameters in the utility model we specify. Alternatively, we can restrict $\phi$ to be a function of interactions between degree and student characteristics. This approach is consistent with general models of choice and, unlike the first approach, appears to be supported by current survey evidence as well as evidence from choice and earnings data. We follow this second approach.

Specifically, we allow earnings for individual $i$ to be a function of the degree-level effect, $\theta_{p}$, and an additional comparative advantage term, $\phi_{i p}$, which varies with observable school and student characteristics. Let $g$ denote a cell defined by a triplet of student characteristics $c$, field of study $f$, and selectivity quartile $s$. We allow that $\phi_{i p}=\phi_{g(i, p)}$, so that for individual $i$ with characteristics $c$ applying to degree $p$,

$$
Y_{i c p}=f_{c p}\left(d_{i p}\right)+\sum_{r=1}^{P}\left(\theta_{r}+\phi^{\prime} X_{g}\right) A_{i r}+\varepsilon_{i p}
$$

where $X_{g}$ is a vector of indicator variables for each group $g$ defined above, $\phi$ is a vector of coefficients $\phi_{g}, P$ is the total number of degrees, $A_{i r}$ is an indicator if $i$ was admitted to program $r$, and $f_{c p}\left(d_{i p}\right)$ is a smooth degree-and-student-characteristic-specific functions of $d_{i p}$. We instrument for $A_{i r}$ and its interaction with $X_{g}$ using a set of threshold-crossing indicators $Z_{i c r}$ which are equal to one if applicant $i$ to degree $r$ with characteristic $c$ has $d_{i r} \geq 0$.

We estimate (4) under four alternative assumptions. First, we assume that students choose degrees on the basis of characteristics other than earnings or on the basis of mean earnings effects $\theta_{p}$, so that mean values of the $\phi_{i p}$ for students at each threshold are equal to population means. We refer to this as the homogeneous effects model. We restrict the $f_{c p}\left(d_{i p}\right)=f_{p}\left(d_{i p}\right)$ for all $c$, and instrument using $Z_{i r}=1\left[d_{i r}>0\right]$. This yields a just-identified IV specification with $P$ endogenous admissions outcomes and $P$ threshold-crossing indicators. Intuitively, estimating the homogeneous effects model amounts to solving $P$ equations of the form given in (3) for $P$ unknowns, $\theta$, using the threshold-crossing estimates $\Delta$ and transition probabilities $\pi$.

We then estimate three "comparative advantage" models, where students may anticipate differential returns to different degrees by gender, socioeconomic status (SES), or measured skills, and 
select degrees accordingly. ${ }^{27}$ We define SES as either high (for students in approximately the top $40 \%$ of high schools by student income) or low (for students in the bottom 60\%). This specification allows for a different impact of admission on high- versus low-SES students by degree category. We divide students into three groups based on measured skill: a "comparative advantage math" group whose math test scores exceed their reading test score by at least 50 points, a "comparative advantage reading" group whose reading scores exceed their math scores by at least 50 points, and a "no comparative advantage" group whose math and reading scores fall within 50 points of one another. One might expect students with a comparative advantage in math to perform relatively better at math-intensive degrees in science or technology.

Note that these restrictions apply to the factors that drive degree choice, not to all heterogeneity in degree-specific earnings effects. For example, if students have uniform evaluations of degrees and expected earnings, perhaps as a function of degree selectivity or prestige,$^{28}$ then the $\phi_{i p}$ may not drive choice even if they affect earnings outcomes. If expected deviations from degree-specific earnings effects are less important to students than fit (i.e., "doing what you love") when selecting field of study, then the $\phi_{i p}$ may not drive choice. Generally speaking, we will obtain consistent estimates of treatment effects when students are either a) unaware of their idiosyncratic degree-specific earnings effects or b) place little weight on earnings in degree selection, and c) preferences over other degree attributes are not correlated with individual-specific comparative advantage.

To see this, consider a choice of degree where person $i$ 's beliefs about expected earnings at the time of enrollment are given by $\tilde{Y}_{i p}=\rho_{i} \mu_{i}+\gamma_{i} \theta_{p}+\lambda_{i} \phi_{i p}$, where $\rho_{i}, \gamma_{i}, \lambda_{i}$ permit deviations in beliefs about future earnings determinants from own, degree, and own-degree components. Individual $i$ chooses a degree from among degrees she can get into to maximize utility, $U_{i p}=\pi_{i} \tilde{Y}_{i p}+V_{i p}=\eta_{i} \mu_{i}+\alpha_{i} \theta_{p}+\beta_{i} \phi_{i p}+V_{i p}$, where $V_{i p}$ is the non-earnings-related value to $i$ of attending $p$, such as tuition, expected vocational enjoyment (e.g. $i$ likes writing and $p$ is a degree in journalism), the selectivity or social prestige of the institution and degree, the attractiveness and fit of the campus and student body. If $\lambda_{i}=0$ (students are unware of their own comparative advantage) or $\pi_{i}=0$ (students do not weight earnings outcomes in college choice, and $V_{i p}$ is uncorrelated with $\phi_{i p}$, then homogeneous effects models will return unbiased

\footnotetext{
${ }^{27}$ These are over-identified specifications, with $C P$ threshold-crossing variables as instruments and $P+(C-1) G$ endogenous variables, where $\mathrm{C}$ is the number of categories into which we divide students and $\mathrm{G}$ is the number categories into which we divide degree programs.

${ }^{28}$ See for example Winston 1999, Epple et al. 2013, Hastings et al. 2014, Hastings, Neilson and Zimmerman 2014a,b.
} 
estimates of $\theta_{p}{ }^{29}$ Alternatively, if $V_{i p}$ is correlated with $\phi_{i p}$ only through characteristics observable to the econometrician, then the heterogeneous effects model based on observables will capture heterogeneity in earnings gains without imposing strict distributional assumptions on beliefs.

Several types of evidence indicate that these assumptions are more consistent with the data than the alternative of a fully-informed, forward-looking, and rational model of degree choice. First, we find no evidence of selection into degree programs on the basis of observable comparative advantage. Male students, students from high-SES backgrounds, and strong math students are no more likely to apply to degree programs where students like them earn more. In contrast, high-SES students and male students do appear to select into degrees where all students earn more. We discuss these results in Section 5.3.

Second, our findings are consistent with current empirical evidence on the determinants of degree choice. This literature suggests that students choose degrees with access to limited information on earnings outcomes and with a heavy emphasis on non-pecuniary characteristics. Hastings et al. (2014) analyze survey data from tens of thousands of Chilean college applicants and college students. They find that the majority of respondents list prestige and accreditation as the primary reason for degree selection while only $11 \%$ list future earnings as one of their top three determinants of degree choice (only $2 \%$ list it as their top reason). Given a hypothetical question about willingness to switch careers in response to economy-wide changes in relative earnings, over $43 \%$ say they would never change their career in response to relative earnings changes. ${ }^{30}$ Between $35 \%$ and $47 \%$ of applicants do not know what they will expect to earn as graduates from their chosen degrees.

Other authors find similar results in different contexts. Though few estimates of institutionspecific earnings expectations are available, evidence from papers such as Pallais (2009) and Avery and Hoxby (2004) suggests that institution choice depends heavily on the framing of choice options and financial aid outcomes. ${ }^{31}$ Wiswall and Zafar (2013) present evidence that even enrolled undergraduates at highly selective US institutions - a group well situated to make informed choices-- are poorly informed about the distribution of earnings outcomes across field of study, and that tastes, rather than earnings, are the primary determinant of major choice. More broadly, Hastings, Neilson and Zimmerman (2014) analyze student choice and market response to the expansion of student loans in Chile and show that

\footnotetext{
${ }^{29}$ Intuitively, in a dichotomous choice between two degrees, the expected earnings for those admitted to $p$ instead of an alternative degree 0 are $E\left(\Delta Y_{i} \mid \alpha_{i} \Delta \theta+\beta_{i} \Delta \phi_{i}+\Delta V_{i}>0\right)$, where $\Delta$ denotes the difference between the value at degree $p$ versus degree 0 .

${ }^{30}$ The question specifically asked "Suppose that INE [the National Labor Institute] just released a new report that proves that the salaries for graduates in [first choice field] have fallen by $10 \%$. Now, instead of earning [respondent estimate of earnings in that field], you will earn [X\% less than expected value]. Would you feel the need to change this career option for another?" $\mathrm{X}$ increased if the respondent answered "no", from $10 \%$ to $50 \%$, at which point respondents could click "never" or fill in a value higher than $50 \%$ for the wage change it would take to induce them to switch careers.

${ }^{31}$ See Scott-Clayton (2012) for a review, and Hastings, Madrian, \& Skimmyhorn (2013) for a discussion of market conditions that may reduce incentives for firms to educate consumers.
} 
enrollment and tuition responses from schools are consistent with a market where students value selectivity as a measure of degree quality (which is a homogeneous degree attribute) and tuition net of loan caps (out-of-pocket up-front cost).

Finally, we will show that allowing for comparative advantage in terms of gender, SES, and relative skill produces estimates very similar to those obtained under the assumption of homogeneous degree effects. In sum, the four models we estimate capture key features of choices and earnings outcomes, and allow us to estimate returns by degree from regression discontinuity estimates without imposing a full set of structural assumptions on degree choice, earnings expectations, and realized earnings. We can use these estimates to shed light on key policy questions around how returns vary with field of study, selectivity and student demographics.

\subsection{Estimation details}

We estimate (1) and (4) using data on mean 2005-2012 earnings. We exclude applicant-year observations for which fewer than six years have elapsed since the year of college application. We include observations with zero earnings values in our regressions. We focus our analysis on a 25-point window on either side of admissions cutoff values, and include second-order polynomials in score. The polynomials are allowed to change above and below the cutoff value. Because individuals can appear at more than one threshold (they may just fail to be admitted to $p$ and just cross the threshold to $q$ ), we cluster standard errors at the individual level. Cluster - robust standard errors are computed using a wild-bootstrap procedure (Cameron et al. 2008, Davidson and MacKinnon 2010). The wild bootstrap allows us to conduct analysis and robustness checks outside of the tax authority using only degree and characteristic specific threshold-crossing estimates, and ensures that the population of students at each threshold is fixed across bootstrap replications. Online Appendix Section VI provides further details on the estimation procedure.

After computing the threshold-crossing and model estimates for each degree program, we summarize the distribution of estimates by program selectivity and field of study, weighting by counts of marginal applicants. We focus on group-specific means, but in addition present results from various quantiles of the earnings distribution. For our comparative advantage models, we present estimates of treatment-on-the-treated effects, weighting by counts of marginal applicants within demographic groups. Online Appendix Section VII presents several robustness checks. We present standard robustness checks varying the bandwidth around the threshold and the polynomial degree (Imbens and Lemieux 2008; Lee and Lemieux 2010). We also vary our definition of degree-year pairs with excess demand, and present 
estimates that allow for unrestricted variation in degree effects by demographic group. Our findings are robust to these changes.

\section{Results}

\subsection{Threshold-crossing effects}

We first consider standard tests of RD validity. If students are unaware of admissions cutoffs when taking exams and making application decisions, they should be unable to target their scores so as to just exceed the admissions threshold (McCrary 2008). Figure 1 presents a histogram of scores relative to the threshold value, using data pooled across all applications. There is no evidence of discontinuous clumping in the distribution of scores above the threshold. In addition, if the regression-discontinuity design is valid, observable and unobservable characteristics of students will be balanced across the admissions threshold (Lee 2007). Figure 2 plots an index of baseline characteristics against distance from the admission cutoff. The index is the portion of earnings predicted by baseline characteristics in an OLS regression of labor market earnings that also controls for polynomials in score and cohort and experience effects. Baseline characteristics include gender, high school type (dummies for private and voucher high schools), and cohort. There is no visible discontinuity around the threshold. Table 2 presents the impact of threshold crossing on baseline characteristics, pooled as well as by the degree characteristics of interest (field, coursework, selectivity). Magnitudes of estimated discontinuities are uniformly small, and differ statistically from zero at the ten percent level in only one of 15 joint or pooled tests. See Online Appendix Section VII for additional graphical tests of baseline characteristic balance.

Figure 3 plots matriculation into the target institution-degree against distance from the cutoff score for applications from 2000 to 2011 . Recall that we currently only have complete matriculation records for these years. As reported in the final column of Table 2, threshold crossing causes a 49.9 percentage point increase in the probability of matriculating in the target degree. This is less than 100 percentage points because admitted students may opt not to enroll to pursue alternative plans or try again next year for a higher ranked choice, and because non-admitted students may be pulled off the waitlist. Waitlist effects are visible among score bins just to the left of the cutoff. Table 2 also breaks down the matriculation effects of admission by field of study and selectivity. Law, Humanities, and Science/Technology degrees have the largest matriculation effects, while Art/Architecture and Education degrees have the smallest. Matriculation rates are larger for more selective degrees, which may be because they are higher ranked choices on average.

Threshold-crossing effects capture the earnings impact of being admitted to the target degree program relative to the mix of degrees where students would otherwise have been admitted. This mix 
varies across target degrees. Table 3 describes acceptance outcomes for students just below the threshold for admission to different types of target degrees. ${ }^{32}$ If rejected students are accepted elsewhere, they are most likely to be accepted to a degree in the same field. For instance, $32.3 \%$ of rejected business degree applicants are accepted to another business degree. Outcomes also vary by selectivity of the target program. $56.6 \%$ of students rejected from programs of above-median selectivity are accepted at other such programs, while $17.7 \%$ are accepted at lower-selectivity programs and $25.6 \%$ end up in the outside option. The equivalent figures for students rejected from below-median selectivity programs are $4.4 \%$, $44.6 \%$, and $51.0 \%$. These patterns suggest that threshold-crossing estimates understate the differences in earnings effects between students applying to high-return fields or high-selectivity degrees compared to low-return fields or low-selectivity degrees, since their below-threshold outcomes likely provide relatively large earnings gains compared to the below-threshold outcomes for applicants to lower-return degrees.

\subsection{Impact on labor market outcomes by program characteristics}

\subsubsection{Degree selectivity}

The first two columns of Table 4 display means of the estimated degree-specific threshold-crossing effects, pooled over all degrees and disaggregated by selectivity. We present earnings effects as percentages of average earnings in the tax records -8.83 million pesos. A coefficient of 0.1 implies that annual earnings gains are equal to $0.1 * 8.83$ million pesos, or about $\$ 1,800 \mathrm{USD} .{ }^{33}$ When computing means across degree programs, we weight by the counts of marginal students at each degree. Overall, crossing the threshold for admission to a target degree program raises earnings by $4.5 \%$ of average earnings. If we restrict our analysis to students applying between 1982 and 1989, that value rises to 8.2\%. Both estimates differ significantly from zero at the $1 \%$ level. Mean threshold-crossing effects rise with the selectivity of the target degree. In the full sample, they grow from $2.0 \%$ in the lowest selectivity quartile, to $3.7 \%$ and $3.4 \%$ in the middle two quartiles, to $9.1 \%$ in the top quartile. Effects in the $1982-1989$ sample follow a similar pattern, but with effect estimates reaching $23.4 \%$ for the most selective degrees. Figures 4 and 5 present graphical evidence of earnings discontinuities from pooled specifications. ${ }^{34}$

The remaining columns of Table 4 present instrumental variables estimates of degree program effects that account for differences in the composition of below-threshold admissions outcomes and allow for various forms of heterogeneity in program effects. Column 3 presents estimates under the assumption

\footnotetext{
${ }^{32}$ These estimates are obtained using local polynomial regressions in the subsample of rejected marginal students.

${ }^{33}$ At an exchange rate of 490 pesos to one US dollar.

${ }^{34}$ Estimates from pooled specifications presented in these and the following figures closely resemble but are not always identical to the estimates aggregated from degree-specific specifications presented in the tables.
} 
of homogeneous program effects $\left(\phi_{i p}=0, \forall i, p\right)$. Columns 4,5 , and 6 present estimates that allow effect to vary by gender, socioeconomic status, and relative proficiency in math and reading, respectively. Because these estimates account for the fact that below-threshold students often attend degrees that are fairly similar to the target degree, they are, on average, larger than threshold-crossing estimates, and rise more with selectivity. In the homogeneous effects model, the mean degree program effect is $12.1 \%$, with effects of $4.7 \%, 8.4 \%, 11.3 \%$, and $24.2 \%$ in selectivity quartiles one through four, respectively. Estimates that allow for heterogeneity in degree effects yield estimates very similar to those in the homogeneous effects model. Column 7 presents estimates for the homogeneous effects model with the sample of 19821989 applicants. As was the case for threshold-crossing estimates, estimated effects are larger within this sample, particularly for the most selective degrees. The pooled average is $15.6 \%$, with degree effects in the top quartile reaching $46.1 \%$.

Figure 6.A. plots point estimates by selectivity bins for the threshold-crossing, homogeneous effects and comparative-advantage models. Earnings effects are small at low selectivity levels, and grow slowly until a score of roughly 650 points, when they begin to grow more rapidly. In Chile, the majority of student loan recipients apply to low-selectivity degrees, and non-selective universities have seen the largest growth in demand during the past decade.

Figure 6.B. shows the distribution of average entrance exam scores for CAE-loan-takers (the main federal loan program) versus non-takers. The bulk of loan takers have entrance exam scores in lower-selectivity range. Hastings, Neilson and Zimmerman (2014) show that loan receipt causes students with test scores in the 475-500 range to substitute away from technical degrees into university degrees at low-selectivity institutions, leaving expected earnings unchanged. Figure 6 and Table 4 add causal evidence consistent with this finding: being admitted to a low-selectivity institution may offer relatively low labor market returns over the outside option (no university, technical or professional degrees per Online Appendix Section I).

Estimated effects are fairly large but not implausible in the context of existing evidence on the returns to selectivity. The average threshold-crossing estimate reflects a gain of $6.8 \%$ relative to belowthreshold earnings (below-threshold-earnings values are on average somewhat smaller than sampleaverage earnings). For comparison, Hoekstra (2009) estimates the earnings gains associated with admission to a state flagship university at between $11 \%$ and $17 \%$, while Zimmerman (2014) estimates the gains associated with admission to the Florida state university system to be between $22 \%$ and $27 \%$. One possible explanation for the smaller effects we find is that students' ability to apply to many fairly similar degree programs at different institutions means their below-threshold outcomes are more similar to above-threshold outcomes than in the U.S. 


\subsubsection{Field of Study}

Differences in returns to selectivity could be generated by differences in field of study that vary systematically across selective and non-selective degree programs. To explore this further, Table 5 shows program returns aggregated by field of study. We present the same specifications as in Table 4 . There is substantial variation in returns by field of study. Means of threshold-crossing effects are largest in the fields of health (10.8\%), social science (8.2\%), and science/technology (4.4\%). Each effect differs significantly from zero at the $1 \%$ level. Threshold-crossing effects do not differ significantly from zero for other fields. The estimated effect for law is relatively large (7\%) but imprecisely estimated, while effects for business and education are positive but small (2.7\% and 1.5\%, respectively) and effects for art/architecture and the humanities are negative (-3\% and $-2.7 \%$, respectively). Estimates are larger and less precise when the sample is limited to the 1982-1989 cohorts. Admission to health, science/technology, law, and social science degrees has the largest earnings effects, although we cannot reject the null that the mean effect for social science degrees is zero. Figure 7 presents graphical evidence of earnings discontinuities by field from pooled specifications.

Model estimates that take into account differences in below-threshold outcomes yield wider gaps in earnings outcomes than do threshold-crossing estimates. Results from the homogeneous effects specification show that admission to a health degree raises earnings by $25.6 \%$ compared to the outside option, admission to a social science degree by $16.1 \%$, admission to a science/technology degree by $11.9 \%$, and admission to a law degree by $15.1 \%$. Effects for business degrees are fairly large (10.1\%) but noisily estimated, while effects for education degrees (4.2\%) are smaller but differ significantly from zero at the ten percent level. Effects for art/architecture and humanities degrees are close zero. We obtain very similar results in models that allow for heterogeneity in degree effects by gender, socioeconomic status, and math and reading skills.

These results suggest that just failing to be admitted to a program of choice could be one of the luckiest or unluckiest events for a student's expected future earnings. Based on results from Column 3, students just admitted to a health degree program rather than education degree program realize an earnings gain of $21.4 \%$, while students admitted to a social science degree program relative to a humanities degree program realize earnings gains of $16.2 \%$.

We next explore the way selectivity effects vary by field. Table 6 combines selectivity measures and field of study by reporting earnings impacts by field for degrees above or below median selectivity (more - or less - selective, respectively). We present the threshold-crossing estimates and the homogeneous effects model estimates only to conserve space. In the health field threshold-crossing effects are of similar (large, positive) sizes at both high and low selectivity levels, while model estimates of degree effects are substantially larger for high-selectivity degrees. Earnings gains for law and social 
science degrees accrue primarily to those admitted to high-selectivity degree programs, while gains are largest at lower selectivity levels for education degrees. Admission to more selective degrees in the humanities and art and architecture leads to earnings losses, although these effects are imprecisely estimated.

As was the case with our estimates by selectivity, our model estimates by field of study are consistent with existing research. Our estimates generally have the same sign but smaller magnitudes than prior estimates of conditional correlations based on enrollment or graduation outcomes (rather than causal estimates of admissions effects). For example, Altonji et al. (2012) find a difference of 24 log points (27\%) for men who study nursing rather than history; the difference between our estimates of the earnings effect of health degrees relative to humanities degrees is roughly $26 \%$. Altonji et al. find a difference of $30.3 \log$ points (35\%) between earnings for biology and elementary education majors; the difference between our estimates of the earnings effects of science/technology and education degrees is roughly $8 \%$.

\subsubsection{Quantiles of effect distributions}

Thus far, our discussion has focused on mean effects within selectivity and field of study groups. The distribution of effects within these groups is also of interest. Table 7 presents within-group standard deviations of effect estimates, as well as $25^{\text {th }}, 50^{\text {th }}$, and $75^{\text {th }}$ percentiles. Within-group variation-which includes measurement error-is large relative to between-group effects. Pooling over all degree programs, the mean threshold-crossing effect is 0.045 , with a standard deviation of 0.241 and a interquartile range of 0.237 . For the most selective degrees, the mean threshold-crossing effect is 0.091 , while the $25^{\text {th }}$ percentile effect is -0.032 and the $75^{\text {th }}$ percentile effect is 0.242 . Overall, however, quantile effects follow a very similar pattern to mean effects. Degree types with higher mean effects tend to exhibit larger effects across quantiles of the effect distribution. This is true for both threshold-crossing and model estimates. Figure 8 illustrates these findings with estimates of the densities of effect distributions for selected fields of study and selectivity groups.

\subsection{Selection into degree programs}

Interpreting our instrumental variables estimates as the earnings effects of admission to a degree program relative to the outside option of no selective degree program depends on the assumption that students do not select into degrees in a way that is correlated with heterogeneous degree effects. In this section, we explore the relationship between estimates of heterogeneous earnings effects based on observable characteristics and selection into degree programs. Recall from Section 4 that in our heterogeneous effects models the earnings effect for a given degree program $r$ can be written $\theta_{r}+\phi^{\prime} X_{g}$, where $\theta_{r}$ is a degree- 
specific intercept term and $X_{g}$ is a vector of interaction dummies between degree field and selectivity and a binary or categorical student covariate $c$. That is, $g=g(c, \mathrm{p})$. The $\phi^{\prime} X_{g}$ are heterogeneous effects for students in category $c$. To assess the importance of selection on heterogeneity, we estimate equations of the form

$$
\hat{\phi}^{\prime} X_{g(c, p)}=\beta_{0}+\beta_{1} s_{c p}+e_{c p}
$$

where $\hat{\phi}$ are the estimated values of $\phi$ and $s_{c p}$ is the share of type $c$ students on the margin of admission to degree $p$. The goal is to understand whether students with a given characteristic sort into degree programs where they have comparative advantage. We also consider specifications in which degreespecific intercept terms $\hat{\theta}_{p}$ are the dependent variables.

The top panel of Table 8 displays medians and standard deviations of population shares $S_{c p}$,

degree-specific intercepts $\hat{\theta}_{p}$, and heterogeneity terms $\hat{\phi}^{\prime} X_{g}$ for the characteristics denoted in the column headings. Standard deviations of estimated heterogeneity terms are roughly one third to one half the size of standard deviations of degree intercepts. The bottom panel of Table 8 shows regression estimates of $\beta_{1}$. The upper set of estimates uses the linear specification from Equation 5, while the lower set uses a binary independent variable equal to one if the population share for characteristic $c$ in degree $p$ is above the median across all degree programs.

There is no evidence that the share of students with high-SES backgrounds, male students, or students with a comparative advantage in math is related to degree-specific comparative advantage for those students. In contrast, students from high-SES backgrounds appear to select into degrees with larger degree effects for all students. There is some evidence that male students do as well. These findings are consistent with survey results indicating that students are poorly informed about the earnings outcomes associated with particular degree programs, and with the finding that model estimates of treatment effects are not substantially changed by allowing degree effects to vary with student observables.

\section{Extensions}

\subsection{Returns to selectivity and field of study by demographics}

Table 9 presents estimates of heterogeneous effects by student socioeconomic background. We focus on estimates from the homogeneous effects model. Table A.VII.II presents parallel estimates of threshold- 
crossing effects. The upper panel of Table 9 shows that degree effects for high- and low-SES students follow similar paths as selectivity rises. Effects in the top selectivity quartile reach $22.6 \%$ for high-SES students and $18.4 \%$ for low-SES students. Both effects differ statistically from zero at the one percent level, and we cannot reject the null that they are equal at conventional levels. The lower panel of Table 9 considers degree effects by field, broken down into above-median and below-median selectivity groups. There are a number of interesting points of contrast. First, students from high-SES backgrounds realize very large earnings benefits (30.7\%) from admission to selective business degrees. The estimated effect for students from low-SES backgrounds is near zero. Second, although the effects of admission to highselectivity health degrees are large and positive for both high- and low-SES students, only low-SES students realize large gains when admitted to low-SES health degrees.

Overall, our results suggest that low-SES students on the margin of admission to elite degree programs can, in many cases, benefit substantially from targeted admissions and scholarship programs. ${ }^{35}$ However, this may not hold across all fields of study. The finding of near-zero earnings effects for lowSES students at high-selectivity business degrees is consistent with Zimmerman (2014), which presents evidence that gains in occupational status from admission to elite business-oriented degree programs are driven by peer ties formed at college between students from elite social backgrounds.

Table A.VII.III presents model estimates and threshold-crossing effects separately for men and women. We find few differences by gender within fields or within selectivity levels. The main exception is health degrees, where men earn substantially more than women. This segment of the market includes the most prestigious degrees in medicine (doctors) as well as nurses, pharmacists and other medical specialties. One interpretation in the literature consistent with our finding of small gender differences in earnings is that non-pecuniary differences in fields drive choices more than do pecuniary differences. For example, women may have preferences related to the fraction of women in the field or work schedule and career trajectory overlap with reproductive age. ${ }^{36}$

\subsection{Curriculum Focus}

Some policy makers have called for the re-focus of federal grants and loans towards degrees that train students for particular jobs upon graduation. ${ }^{37}$ The assumption is that vocational training improves labor

\footnotetext{
${ }^{35}$ Bertrand, Hanna and Mulainathan (2009) examine returns to affirmative action programs in India. They find that lower-scoring lower-caste entrants have positive returns to admission, but that these returns are lower than those for higher-scoring higher-caste members. Our regression discontinuity design implies that scores are on average the same across applicants from different socioeconomic backgrounds. Conditional on score, lower-SES students appear to gain as much as higher-SES students.

${ }^{36}$ See for example Goldin and Katz (2008), Bertrand, Goldin and Katz (2010), and Bertrand (2011) and cites contained therein.

${ }^{37}$ See for example the U.S. Higher Education Reform and Opportunity Act, http://www.lee.senate.gov/public/index.cfm/pressreleases?ID=c7dc39c0-cfa8-425a-9528-7cc6e307fef2. Accessed September 18, 2014.
} 
market outcomes. We use course requirement data to categorize degrees by curricular focus, and examine how earnings outcomes differ between vocational and core-curriculum degrees.

Because historical information on course requirements in not available, we use current course requirements as listed on institution websites. Vocational courses include internships and courses that teach students how to apply skills specific to segments of the labor market. A course on medical device operation and repair would fall into this category, but a course on chemistry or cell biology would not. Degrees with an above-median fraction of vocational course requirements are categorized as a vocational degree. See Online Appendix V.III for a discussion of course categorization.

Appendix Table A.VII.VI presents the results. We do not find evidence that vocationally-oriented degrees result in higher earnings. Rather, we find that within selectivity tiers, degrees with a corecurriculum focus lead to larger earnings gains. One interpretation of these findings is that students receiving broad training in logic and language skills may more successfully adapt to a changing labor market over their career, resulting in larger long-run earnings gains.

\subsection{Tuition and net returns to admission}

One concern is that the benefits students realize from admission to different degrees may simply be captured by universities through higher tuition costs. Because tuition and matriculation data are not systematically available for earlier years, we construct estimates of the direct costs of college for the 2007 applicant cohort using data on observed matriculation and tuition payments for the years 2007 to 2012 . We compute total costs for marginal admitted students over the six years following application, and compare them to our homogeneous effects model estimates. We interpret the side-by-side comparison as the cost-benefit tradeoff a student today would face when considering which degree to apply to, given information about earnings gains for past cohorts and current tuition costs. These results should be viewed cautiously, because they take into account neither lost early-career earnings nor possible tuition expenses at non-selective degrees, which accounted for a large share of enrollment by the late $2000 \mathrm{~s}$.

Table 10 shows the estimated earnings gains and tuition costs by field and selectivity tier. The highest earning field, health, has the highest tuition, but tuition costs are small relative to increased average annual earnings gains over lower-earning fields. Degrees in art and architecture appear to be the worst deal, with lower expected earnings gains and similar tuition costs to social science, business, and science/technology degrees. To make this comparison more concrete, we compute the present discounted values of tuition payments and expected earnings gains over the life cycle (PDVs). ${ }^{38} \mathrm{PDV}$ s of health,

\footnotetext{
${ }^{38} \mathrm{We}$ assume an interest rate of $6 \%$, and that earnings benefits accrue for years 7 through 48 of following application, or approximately ages 25 through 65 .
} 
social science, law, and technology degrees are positive, while PDVs for art/architecture and humanities degrees are large and negative.

Tuition costs increase with selectivity of the degree. The most selective degrees charge almost two times more tuition than the least selective degrees. However, expected annual earnings gains are almost five times as high. PDV calculations suggest that low-selectivity degrees have a negative return, while the returns to the most selective degrees are large and positive. Institutions do not appear to be fully capturing differences in earnings gains with increased tuition.

\subsection{Possible mechanism: Increased educational attainment}

Across a variety of specifications, we find that admission to selective degrees and degrees with a focus on health, social science, or science/technology yield positive and significant earnings gains. These gains do not appear to be fully captured by higher tuition. Our results are consistent with a number of underlying mechanisms. One possibility is that admission to more selective degree programs or degree programs in certain fields tends to raise overall educational attainment and college graduation rates, which may affect earnings through signaling or human capital accumulation. Cohodes and Goodman (2014), Goodman et al. (2014), and Zimmerman (2014) provide evidence from the U.S. that attending a more selective university tends to raise graduation rates. Using matriculation and graduation records from 2000-2011, Online Appendix section VIII shows how matriculation translates into degree completion by selectivity and field of study. Overall, more selective degrees are more effective at graduating students; students crossing the threshold into a more selective degree are about 1.73 times more likely to graduate from the target degree than students crossing a threshold into a less-selective degree are. Graduation and earnings gains are linked through student choice: if students realize after matriculation that their degree will result in lower earnings than expected they may be inclined to drop out sooner (Hastings et al. 2013a). They are both likely correlated with student ability and socioeconomic status as well. Decomposing the factors that contribute to the high returns observed for selective degrees is an important area for future research.

\section{Conclusion}

We exploit discontinuous admissions rules at more than 1,100 degree programs to examine the way the effects of college admission on labor market earnings vary by degree selectivity, field of study, and student background. We find statistically and economically significant heterogeneity in the earnings gains associated with crossing an admissions threshold by selectivity and field of study. These differences are 
not driven by correlations in preferences and/or unobserved skill (e.g. Dahl, 2002), as both are balanced across admission thresholds.

In addition to presenting threshold-crossing estimates, we use variation in admissions outcomes generated by the set of discontinuities to identify a simple model of earnings determination that accounts for differences in below-threshold educational outcomes across degree programs. These estimates, which rely on assumptions about the choice process that we test using a combination of in-sample and survey evidence, allow us to draw policy-relevant conclusions about the earnings effects of each degree program relative to a common baseline of not attending any selective degree program. Model estimates suggest that earnings gains grow more with selectivity than indicated by threshold-crossing results alone. Low selectivity degrees do not raise earnings very much on average, with degrees in the health field being a notable exception. Our results provide insight into a number of policy debates. Earnings gains associated with admission to highly selective degrees are just as large for students from low-SES backgrounds as those for students from high-SES backgrounds. This is consistent with the idea that interventions aimed at helping poor but qualified students gain admission to elite universities is welfare improving (Hoxby and Turner 2013). Students from high-SES backgrounds benefit disproportionately from access to selective business degrees, consistent with findings from Zimmerman (2014) that occupational gains from such degrees are largely driven by peer ties formed between students from wealthy backgrounds. We also find little evidence of differing earnings returns for men and women. This suggests that the large differences in major choice for men and women (Turner and Bowen 1999; Zafar 2013) may be driven not by differences in earnings outcomes, but by differences in non-pecuniary characteristics.

More broadly, our findings suggest that frictions exist in the markets that match students to postsecondary degrees. Constraints on the supply of high-return degrees (see Bound and Turner 2007; Zimmerman 2014) may push students into programs with lower economic returns at many margins. Admitting the marginal applicant to a high-return program by lowering the score cutoff a small amount would likely have a positive social return. At the same time, we observe excess demand for degrees that do not raise earnings for admitted students. This could be because these degrees offer high non-pecuniary compensation that is valued by all students, or because some students have very strong tastes for the coursework or careers associated with these degrees.

Hastings et al. (2014a) present evidence suggesting that students may base college choices on beliefs about economic returns that are systematically biased and uninformed. The existence of oversubscribed degrees with zero or negative returns thus suggests two possible avenues for welfareimproving policy intervention. First, if information aggregation is a public good, policymakers could supply centralized ranking and earnings information to provide students with added information needed for making life-long decisions (Beyer et al. 2014, Hastings et al. 2014a,b). Second, loan policy could be 
used to provide additional supply-side incentives to ease frictions in supply of high-return degrees (Beyer et al., 2014).

\section{References}

Altonji, Joseph, Erica Blom and Costas Meghir. 2012. "Heterogeneity in Human Capital Investments: High School Curriculum, College Major, and Careers," Annual Review of Economics, vol. 4(1): 185223, 07.

Arcidiacono, Peter. 2004. "Ability sorting and the returns to college major." Journal of Econometrics, 121: 343-375.

Arcidiacono, Peter, Patrick Bayer and Aurel Hizmo. 2010. "Beyond Signaling and Human Capital: Education and the Revelation of Ability," American Economic Journal: Applied Economics, vol. 2(4): 76-104, October.

Autor, David H., Lawrence F. Katz and Melissa S. Kearney. 2008. "Trends in U.S. Wage Inequality: Revising the Revisionists." Review of Economics and Statistics, 90(2): 300-323.

Azevedo, Eduardo and Jacob Leshno. 2014. "A supply and demand framework for two-sided matching markets." Unpublished (under revision).

Beffy, Magali, Denis Fougère and Arnaud Maurel. 2012. "Choosing the Field of Study in Postsecondary Education: Do Expected Earnings Matter?," The Review of Economics and Statistics, vol. 94(1): 334347, February.

Bertrand, Marianne. 2011. "New Perspectives on Gender.” Handbook of Labor Economics, Vol. 4(B): 1543-1590. Elsevier B.V.

Bertrand, Marianne, Claudia Goldin, and Lawrence F. Katz. 2010. "Dynamics of the Gender Gap for Young Professionals in the Financial and Corporate Sectors." American Economic Journal: Applied Economics, 2(3): 228-55.

Bertrand, Marianne, Rema Hanna and Sendhil Mullainathan. 2009. "Affirmative Action in Education: Evidence from Engineering College Admissions in India." Journal of Public Economics, 94(1-2):1629.

Beyer, Harald, Justine Hastings, Christopher Neilson, Phillip Ross, and Seth Zimmerman. 2014 "Earnings, Incentives and Student Loan Design: The Case of Chile." Unpublished Manuscript, Brown University.

Black, Dan A. and Jeffrey A. Smith. 2004. "How Robust is the Evidence on the Effects of College Quality? Evidence from Matching." Journal of Econometrics, 121(1-2): 99-124.

Black, Dan and Jeffrey Smith. 2006. "Estimating the Returns to College Quality with Multiple Proxies for Quality," Journal of Labor Economics, vol. 24(3): 701-728, July.

Bound, John and George Johnson. 1992. "Changes in the Structure of Wages in the 1980's: An Evaluation of Alternative Explanations.” American Economic Review, 82(3): 371-392.

Bound, John and Sarah Turner. 2007. "Cohort Crowding: How Resources Affect Collegiate Attainment." Journal of Public Economics, 91(5-6): 877-899.

Braun, Sebastian, Dwenger Nadja and Kübler Dorothea. 2010. "Telling the Truth May Not Pay Off: An Empirical Study of Centralized University Admissions in Germany," The B.E. Journal of Economic Analysis \& Policy, vol. 10(1): 1-38, March.

Cameron, Colin A., Jonah B. Gelbach and Dougleas L. Miller. 2008. "Bootstrap-Based Improvements for Inference with Clustered Errors." The Review of Economics and Statistics, 90(3): 414-427.

Chen, Yan and Onur, Kesten. 2013. "From Boston to Chinese parallel to deferred acceptance: Theory and experiments on a family of school choice mechanisms," Discussion Papers, Research Unit: Market Behavior SP II 2013-205, Social Science Research Center Berlin (WZB). 
Cohodes, Sarah, and Joshua Goodman. 2014 (Forthcoming). Merit Aid, College Quality and College Completion: Massachusetts' Adams Scholarship as an In-Kind Subsidy. American Economic Journal: Applied Economics.

Cutler, David M. and Lawrence F. Katz. 1992. "Rising Inequality? Changes in the Distribution of Income and Consumption in the 1980's." American Economic Review Papers and Proceedings, 82(2): 546551.

Dahl, Gordon. 2002. "Mobility and the Return to Education: Testing a Roy Model with Multiple Markets." Econometrica, 70(6): 2367-2420.

Dale, Stacy B. and Alan B. Krueger. 2002. "Estimating the Payoff to Attending a More Selective College: an Application of Selection on Observables and Unobservables." Quarterly Journal of Economics, 117(4): 1491-1528.

Dale, Stacy B. and Alan B. Krueger. 2011. "Estimating the Return to College Selectivity over the Career Using Administrative Earnings Data.” Mathematica Policy Research Reports 6922.

Davidson Russell and James G. MacKinnon. 2010. "Wild Bootstrap Tests for IV Regression.” Journal of Business \& Economic Statistics, 28(1): 128-144.

Deming, David J., Claudia Goldin and Lawrence F. Katz. 2012. "The For-Profit Postsecondary School Sector: Nimble Critters or Agile Predators?” Journal of Economic Perspective, 26(1): 139-164.

Deming, David J., Justine S. Hastings, Thomas J. Kane and Douglas O. Staiger. 2014. "School Choice, School Quality, and Postsecondary Attainment," American Economic Review, vol. 104(3): 991-1013, March.

Epple, Dennis, Richard Romano, Sinan Sarpca and Holger Sieg. 2013. "The U.S. Market for Higher Education: A General Equilibrium Analysis of State and Private Colleges and Public Funding Policies." NBER Working Paper No. 19298.

Goldin, Claudia and Lawrence F. Katz. 2007. "Long-Run Changes in the Wage Structure: Narrowing, Widening, Polarizing." Brookings Papers on Economic Activity, 38(2): 135-168.

Goldin, Claudia and Lawrence F. Katz. 2008. "Transitions: Career and Family Life Cycles of the Educational Elite.” American Economic Review, 98(2): 363-69.

Goodman, Joshua, Michael Hurwitz, and Jonathan Smith. "College Access, Initial College Choice and Degree Completion." HKS Faculty Research Working Paper Series RWP14-030, June 2014.

Hastings, Justine S., Brigitte C. Madrian and William L. Skimmyhorn. 2013. "Financial Literacy, Financial Education, and Economic Outcomes," Annual Review of Economics, vol. 5(1): 347-373, 05.

Hastings, Justine, Christopher Neilson, Anely Ramirez, Philip Ross, Unika Shrestha, and Seth Zimmerman. 2014. "(Un)informed College Choice: Evidence from Chile.” Unpublished manuscript. Brown University.

Hastings, Justine, Christopher Neilson, Anely Ramirez, and Seth Zimmerman. 2014a. "Student Loans, College Choice and the Returns to Higher Education." Unpublished manuscript. Brown University.

Hastings, Justine, Christopher Neilson and Seth Zimmerman. 2014b. "The Impact of Student Loans on Postsecondary Education Markets: Evidence from Chile.” Unpublished manuscript. Brown University.

Hoekstra, Mark. 2009. "The Effect of Attending the Flagship State University on Earnings: A Discontinuity-Based Approach." The Review of Economics and Statistics. 91(4): 717-724

Hoxby, Caroline M. and Christopher Avery. 2004. "Do and Should Financial Aid Decisions Affect Students' College Choices?" College Choices: The New Economics of Choosing, Attending, and Completing College, C. Hoxby, ed. University of Chicago Press.

Hoxby, Caroline M. and Christopher Avery. 2012. "The Missing "One-Offs": The Hidden Supply of High-Achieving, Low Income Students.” NBER Working Paper No. 18586.

Hoxby, Caroline and Sarah Turner. 2013. "Expanding College Opportunities for High-Achieving, Low Income Students," Discussion Papers, Stanford Institute for Economic Policy Research 12-014, Stanford Institute for Economic Policy Research. 
Heckman, James J., Sergio Urzua and Edward Vytlacil. 2006. "Understanding Instrumental Variables in Models with Essential Heterogeneity," The Review of Economics and Statistics, Vol. 88(3), 389-432.

Imbens, Guido W., and Thomas Lemieux. 2008. "Regression discontinuity designs: A guide to practice." Journal of Econometrics 142, no. 2:615-635.

Jacob, Brian, Brian McCall and Kevin M. Stange. 2013. "College as Country Club: Do Colleges Cater to Students' Preferences for Consumption?" NBER Working Paper No. 18745.

Jensen, Robert. 2010. "The (Perceived) Returns to Education and the Demand for Schooling." The Quarterly Journal of Economics, 125(2): 515-548.

Juhn, Chinhui, Kevin M. Murphy and Brooks Pierce. 1993. "Wage Inequality and the Rise in Returns to Skill.” Journal of Political Economy, 101(3): 410-442.

Kane, Thomas J. and Cecilia E. Rouse. 1995. "Labor Market Returns to Two- and Four-Year Colleges: Is a Credit a Credit and Do Degrees Matter?” American Economic Review, 85(3): 600-614. Karoly, Lynn A. and Gary Burtless. 1995. "Demographic Change, Rising Earnings Inequality, and the Distribution of Personal Well-Being, 1959-1989.” Demography, 32(3): 379-405.

Katz, Lawrence F. and Kevin M. Murphy. 1992. "Changes in Relative Wages, 1963-1987: Supply and Demand Factors.” Quarterly Journal of Economics, 107(1): 35-78.

Lavecchia, Adam M. Heidi Liu and Philip Oreopoulos. 2014. "Behavioral Economics of Education: Progress and Possibilities." Forthcoming. Handbook of Labor Economics. Elsevier.

Lee, David S., and Thomas Lemieux. 2010. "Regression Discontinuity Designs in Economics." Journal of Economic Literature 48, no. 2:281-355.

McCrary, Justin. 2008. "Manipulation of the Running Variable in the Regression Discontinuity Design: A Density Test." Journal of Econometrics. 142 (2): 698-714.

Murphy, Kevin M. and Finis Welch. 1993. "Inequality and Relative Wages.” American Economic Review Papers and Proceedings, 83(2), 104-109.

Öckert, Björn. 2010. "What's the value of an acceptance letter? Using admissions data to estimate the return to college." Economics of Education Review, 29(4): 504-516.

Ozier, Owen. 2013. "The Impact of Secondary Schooling in Kenya: A Regression Discontinuity Analysis." Unpublished. The World Bank.

Pallais, Amanda. 2009. "Taking a Chance on College: Is the Tennessee Education Lottery Scholarship Program a Winner?” Journal of Human Resources, 44 (1): 199-222.

Pop-Eleches, Cristian and Miguel Urquiola. 2013. "Going to a Better School: Effects and Behavioral Responses,” American Economic Review, 103(4): 1289-1324.

Rolando M., Rodrigo, Juan Salamanca V., and Marcelo Aliaga Q. 2010. "Evolución Matrícula Educación Superior de Chile: Periodo 1990 - 2009," Servicio de Información de Educación Superior, Chilean Ministry of Education.

Saavedra, Juan E. 2009. "The Returns to College Quality: A Regression Discontinuity Analysis." Unpublished Manuscript, Harvard University.

Scott-Clayton, Judith. 2012. "Information Constraints and Financial Aid Policy." NBER Working Paper No. 17811.

Solis, Alex. 2013. "Credit Access and College Enrollment," Working Paper Series, Uppsala University, Department of Economics.

Turner, Sarah E. and William G. Bowen. 1999. "Choice of major: The changing (unchanging) gender gap," Industrial and Labor Relations Review, vol. 52(2): 289-313, January.

Winston, Gordon C. 1999. "Subsidies, Hierarchy and Peers: The Awkward Economics of Higher Education." Journal of Economic Perspectives, 13(1): 13-36.

Wiswall, Matthew and Basit Zafar. 2013. "How Do College Students Respond to Public Information about Earnings?" Federal Reserve Bank of New York Staff Reports No. 516.

Zafar, Basit. 2013. "College Major Choice and the Gender Gap," Journal of Human Resources, vol. 48(3): 545-595.

Zimmerman, Seth. Forthcoming. "The Returns to College Admission for Academically Marginal Students," Journal of Labor Economics. 
Table 1: Student Characteristics

(2)

(3)

All Marginal Applicants Estimation Sample

Student characteristics

Male

$52.4 \%$

$55.1 \%$

$55.2 \%$

High SES HS

$40.9 \%$

$45.1 \%$

$45.4 \%$

Math test

613.7

633.9

635.9

Reading test

592.0

602.8

603.9

GPA

575.8

583.3

584.0

\section{Application characteristics}

\begin{tabular}{lccc} 
Accepted & $52.3 \%$ & $42.9 \%$ & $42.9 \%$ \\
Less selective & $47.7 \%$ & $39.1 \%$ & $38.1 \%$ \\
More selective & $53.0 \%$ & $60.9 \%$ & $61.9 \%$ \\
Business & $9.6 \%$ & $11.8 \%$ & $11.8 \%$ \\
Art/Arch. & $6.3 \%$ & $5.6 \%$ & $5.6 \%$ \\
Education & $17.9 \%$ & $13.4 \%$ & $13.4 \%$ \\
Law & $3.9 \%$ & $5.3 \%$ & $5.3 \%$ \\
Health & $11.4 \%$ & $13.1 \%$ & $13.1 \%$ \\
Sci/Tech. & $41.4 \%$ & $43.2 \%$ & $43.2 \%$ \\
Humanities & $2.3 \%$ & $1.8 \%$ & $1.8 \%$ \\
Soc. Sci. & $7.2 \%$ & $5.8 \%$ & $5.8 \%$ \\
& & & \\
Labor market & & & $83.3 \%$ \\
Participation & $82.3 \%$ & $83.2 \%$ & 10.5 \\
Earnings & 8.83 & 10.4 & 770,791 \\
\hline N applications & $2,246,488$ & 796,724 & 469,414 \\
N students & 899,548 & 480,479 & \\
\hline
\end{tabular}

Notes: Notes: Characteristics of full dataset and analysis sample. Data is at the application (i.e., person X program X application year) level. The Marginal Applicants column contains applications that with at least 18 waitlisted individuals with scores within five points of the cutoff, and includes only applications within 25 points above or below the cutoff value. Estimation Sample is the marginal sample with the additional restriction that data on the area and selectivity of the target application be available. Labor market outcomes are for years 6-30 after the application year. Earnings are in millions of 2011 Chilean pesos. Data reflect the 1982-2006 application cohorts. Less-selective and moreselective are defined as degrees with below- or above-median average admission cutoffscore over the 1982-2006 period. 
Table 2: Validating the RD Design

\begin{tabular}{|c|c|c|c|c|c|c|}
\hline & (1) & (2) & (3) & (4) & (5) & (6) \\
\hline & Index+ & Male+++ & Public HS+ & $\begin{array}{c}\text { Private } \\
\text { HS+ }\end{array}$ & $\begin{array}{c}\text { High } \\
\text { SES+++ }\end{array}$ & Matriculation++ \\
\hline \multirow[t]{2}{*}{ Pooled } & 585 & 0.001 & -0.002 & -0.002 & -0.001 & $0.499 * * *$ \\
\hline & $(7,283)$ & $(0.003)$ & (0.003) & $(0.003)$ & $(0.003)$ & $(0.003)$ \\
\hline \multicolumn{7}{|l|}{ Area } \\
\hline \multirow[t]{2}{*}{ Business } & $-19,700$ & $-0.014 *$ & 0.000 & -0.014 & -0.001 & $0.518 * * *$ \\
\hline & $(24,564)$ & (0.008) & $(0.010)$ & $(0.010)$ & $(0.009)$ & $(0.011)$ \\
\hline \multirow[t]{2}{*}{ Art/Arch. } & $-2,741$ & -0.012 & -0.007 & -0.002 & 0.006 & $0.389 * * *$ \\
\hline & $(31,799)$ & $(0.012)$ & (0.013) & $(0.014)$ & $(0.012)$ & $(0.015)$ \\
\hline \multirow[t]{2}{*}{ Education } & $-15,700$ & -0.003 & 0.013 & -0.004 & -0.004 & $0.425 * * *$ \\
\hline & $(13,951)$ & $(0.007)$ & $(0.010)$ & $(0.005)$ & $(0.007)$ & $(0.010)$ \\
\hline \multirow[t]{2}{*}{ Law } & $-18,600$ & $-0.038 * * *$ & -0.009 & 0.001 & 0.010 & $0.636 * * *$ \\
\hline & $(35,371)$ & $(0.012)$ & (0.014) & $(0.014)$ & $(0.012)$ & $(0.013)$ \\
\hline \multirow[t]{2}{*}{ Health } & 11,229 & 0.000 & -0.009 & 0.001 & 0.004 & $0.485 * * *$ \\
\hline & $(18,119)$ & $(0.007)$ & (0.008) & $(0.008)$ & $(0.007)$ & $(0.008)$ \\
\hline \multirow[t]{2}{*}{ Sci/Tech } & $-6,036$ & 0.005 & 0.001 & -0.006 & -0.001 & $0.532 * * *$ \\
\hline & $(11,785)$ & $(0.004)$ & (0.005) & $(0.005)$ & $(0.005)$ & $(0.006)$ \\
\hline \multirow[t]{2}{*}{ Humanities } & $-14,300$ & 0.001 & -0.014 & 0.002 & -0.004 & $0.537 * * *$ \\
\hline & $(45,891)$ & (0.019) & (0.021) & $(0.019)$ & $(0.020)$ & $(0.020)$ \\
\hline \multirow[t]{2}{*}{ Soc. Sci. } & 39,763 & 0.009 & -0.018 & 0.015 & 0.010 & $0.490 * * *$ \\
\hline & $(26,467)$ & $(0.010)$ & (0.011) & $(0.011)$ & $(0.011)$ & $(0.012)$ \\
\hline Joint Test & 0.739 & $0.031^{* *}$ & 0.531 & 0.661 & 0.965 & $0.000 * * *$ \\
\hline \multicolumn{7}{|l|}{ Selectivity } \\
\hline \multirow[t]{2}{*}{ Less } & 6,002 & -0.005 & -0.005 & 0.003 & 0.000 & $0.414 * * *$ \\
\hline & $(8,169)$ & (0.004) & $(0.005)$ & $(0.003)$ & $(0.004)$ & $(0.005)$ \\
\hline \multirow[t]{2}{*}{ More } & $-7,640$ & 0.005 & 0.001 & -0.006 & -0.002 & $0.574 * * *$ \\
\hline & $(10,746)$ & (0.004) & (0.004) & $(0.004)$ & $(0.004)$ & $(0.004)$ \\
\hline Joint Test & 0.593 & 0.138 & 0.546 & 0.221 & 0.814 & $0.000 * * *$ \\
\hline $\mathrm{N}$ applications & 606,323 & $1,011,027$ & 654,671 & 654,918 & 892,513 & 477,044 \\
\hline N students & 360,835 & 602,069 & 385,210 & 385,351 & 526,632 & 292,026 \\
\hline
\end{tabular}


Table 3: Below-threshold Outcomes

\begin{tabular}{|c|c|c|c|c|c|c|c|c|c|c|c|}
\hline & (1) & $(2)$ & (3) & (4) & (5) & (6) & (7) & (8) & (9) & $(10)$ & (11) \\
\hline & All & High-Sel & Low-Sel & Business & Art/Arch. & Education & Law & Health & Sci/Tech. & Hum. & Soc. Sci. \\
\hline All & 63.2 & 33.4 & 29.7 & 6.1 & 2.5 & 8.6 & 2.2 & 7.9 & 28.7 & 1.4 & 3.6 \\
\hline High-Sel & 74.4 & 56.6 & 17.7 & 7.6 & 3.7 & 5.4 & 3.7 & 13.3 & 32.3 & 1.8 & 5.2 \\
\hline Low-Sel & 49.0 & 4.4 & 44.6 & 4.3 & 1.0 & 12.5 & 0.4 & 1.2 & 24.1 & 0.9 & 1.5 \\
\hline Business & 68.6 & 36.0 & 32.6 & 32.3 & 1.3 & 4.3 & 0.5 & 0.4 & 23.8 & 0.5 & 3.4 \\
\hline Art/Arch. & 65.7 & 40.7 & 25.1 & 4.4 & 25.7 & 4.9 & 0.4 & 0.7 & 23.7 & 1.2 & 3.0 \\
\hline Education & 44.9 & 6.4 & 38.4 & 1.3 & 0.8 & 29.0 & 0.5 & 0.8 & 7.7 & 1.7 & 1.2 \\
\hline Law & 75.6 & 53.1 & 21.8 & 4.3 & 1.4 & 5.6 & 32.5 & 1.1 & 5.5 & 5.4 & 16.9 \\
\hline Health & 75.2 & 60.2 & 14.9 & 1.3 & 1.0 & 4.6 & 0.9 & 45.6 & 17.5 & 0.4 & 2.4 \\
\hline Sci/Tech & 62.7 & 29.0 & 33.7 & 3.6 & 1.1 & 4.6 & 0.1 & 1.4 & 48.8 & 0.3 & 0.6 \\
\hline Hum. & 54.7 & 32.4 & 22.2 & 1.2 & 2.8 & 19.7 & 1.4 & 0.0 & 5.1 & 15.7 & 7.3 \\
\hline Soc. Sci. & 65.8 & 38.4 & 27.4 & 5.8 & 3.5 & 11.6 & 3.5 & 1.6 & 8.1 & 5.3 & 22.0 \\
\hline
\end{tabular}

Notes: Estimated intercept effects from regressions of the form given in equation (1), where the dependent variable is an indicator equal to one if the applicant was admitted to a degree of the type listed in the column heading in the same year and the sample is defined as applicants to degrees of the type listed in the row. Estimates reflect the probability of being admitted to a degree of the type indicated in column heading for people who just missed the threshold of admission to a degree of the type indicated in the row label. Units are percentage points. Less-selective and more-selective are defined as degrees with below- or above-median average admission cutoff-scores over the 1982-2006 sample. 
Table 4: Earnings Effects by Selectivity

\begin{tabular}{|c|c|c|c|c|c|c|c|}
\hline \multirow[b]{4}{*}{ Pooled } & $(1)$ & $(2)$ & (3) & $(4)$ & (5) & (6) & $(7)$ \\
\hline & \multicolumn{2}{|c|}{ Threshold-crossing } & \multicolumn{5}{|c|}{ Model estimates } \\
\hline & All years & 1982-1989 & Homogeneous effects & Gender & SES & Skill & 1982-1989 only \\
\hline & $\begin{array}{c}0.045^{* * *} \\
(0.008)\end{array}$ & $\begin{array}{c}0.082^{* * * *} \\
(0.020)\end{array}$ & $\begin{array}{c}0.121^{* * *} \\
(0.033)\end{array}$ & $\begin{array}{c}0.111^{* * *} \\
(0.022)\end{array}$ & $\begin{array}{c}0.105^{* * *} \\
(0.024)\end{array}$ & $\begin{array}{c}0.087 * * * \\
(0.020)\end{array}$ & $\begin{array}{c}0.156 * * * \\
(0.048)\end{array}$ \\
\hline Bottom Quartile & $\begin{array}{c}0.020 * \\
(0.010)\end{array}$ & $\begin{array}{c}0.033 \\
(0.026)\end{array}$ & $\begin{array}{c}0.047 * * \\
(0.021)\end{array}$ & $\begin{array}{c}0.038 * * \\
(0.019)\end{array}$ & $\begin{array}{c}0.019 \\
(0.021)\end{array}$ & $\begin{array}{c}0.022 \\
(0.018)\end{array}$ & $\begin{array}{c}0.062 \\
(0.044)\end{array}$ \\
\hline 2nd Quartile & $\begin{array}{c}0.037 * * * \\
(0.013)\end{array}$ & $\begin{array}{l}0.055^{*} \\
(0.031)\end{array}$ & $\begin{array}{c}0.084 * * * \\
(0.027)\end{array}$ & $\begin{array}{c}0.069 * * * \\
(0.023)\end{array}$ & $\begin{array}{c}0.070 * * * \\
(0.026)\end{array}$ & $\begin{array}{c}0.057 * * \\
(0.023)\end{array}$ & $\begin{array}{l}0.097 * \\
(0.050)\end{array}$ \\
\hline 3rd Quartile & $\begin{array}{c}0.034^{* *} \\
(0.016)\end{array}$ & $\begin{array}{c}0.046 \\
(0.047)\end{array}$ & $\begin{array}{l}0.113 * \\
(0.061)\end{array}$ & $\begin{array}{c}0.102 * * * \\
(0.031)\end{array}$ & $\begin{array}{c}0.111^{* * *} \\
(0.035)\end{array}$ & $\begin{array}{c}0.082 * * * \\
(0.029)\end{array}$ & $\begin{array}{c}0.093 \\
(0.081)\end{array}$ \\
\hline Top Quartile & $\begin{array}{c}0.091 * * * \\
(0.021)\end{array}$ & $\begin{array}{c}0.239 * * * \\
(0.058)\end{array}$ & $\begin{array}{c}0.242^{* * *} \\
(0.053)\end{array}$ & $\begin{array}{c}0.230 * * * \\
(0.043)\end{array}$ & $\begin{array}{c}0.215^{* * *} \\
(0.048)\end{array}$ & $\begin{array}{c}0.185^{* * *} \\
(0.043)\end{array}$ & $\begin{array}{c}0.461^{* * *} \\
(0.113)\end{array}$ \\
\hline $\mathrm{N}$ & 796,724 & 194,895 & 796,724 & 766,462 & 671,040 & 754,396 & 194,895 \\
\hline
\end{tabular}

Notes: Significance at $1 \% \%^{* *}, 5 \% * *$ and $10 \% *$. Columns (1) and (2) reflect application-weighted means of threshold-crossing estimates from equation (1).

Columns (3) through (7) reflect application-weighted means of instrumental variable estimates of equation (4), with comparative advantage terms as specified in the column label. Results are presented for the samples of degrees defined in row labels. Homogeneous effects estimates and 1982-1989 subsample estimates impose the restriction $\phi=0$. Selectivity tier is defined by quartiles of average cutoff values across the 1982-2006 period. Standard errors computed using wild-

bootstrap procedure (Cameron et al. 2008, Davidson and MacKinnon 2010). Online Appendix Sections VI and VII provide further details on estimation. 
Table 5: Earnings Effects by Field of Study

\begin{tabular}{|c|c|c|c|c|c|c|c|}
\hline \multirow{4}{*}{ Business } & $(1)$ & $(2)$ & (3) & (4) & $(5)$ & (6) & $(7)$ \\
\hline & \multicolumn{2}{|c|}{ Threshold crossing } & \multicolumn{5}{|c|}{ Model estimates } \\
\hline & All years & 1982-1989 only & Homogeneous effects & Gender & SES & Skill & 1982-1989 only \\
\hline & $\begin{array}{c}0.027 \\
(0.028)\end{array}$ & $\begin{array}{c}0.077 \\
(0.077)\end{array}$ & $\begin{array}{c}0.101 \\
(0.114)\end{array}$ & $\begin{array}{l}0.102 * * \\
(0.050)\end{array}$ & $\begin{array}{c}0.108 * * \\
(0.053)\end{array}$ & $\begin{array}{c}0.092 * * \\
(0.046)\end{array}$ & $\begin{array}{c}0.145 \\
(0.118)\end{array}$ \\
\hline Art/Arch. & $\begin{array}{l}-0.030 \\
(0.029)\end{array}$ & $\begin{array}{l}-0.021 \\
(0.091)\end{array}$ & $\begin{array}{c}0.014 \\
(0.049)\end{array}$ & $\begin{array}{c}0.016 \\
(0.044)\end{array}$ & $\begin{array}{l}-0.021 \\
(0.049)\end{array}$ & $\begin{array}{l}-0.017 \\
(0.045)\end{array}$ & $\begin{array}{c}0.072 \\
(0.124)\end{array}$ \\
\hline Education & $\begin{array}{c}0.015 \\
(0.014)\end{array}$ & $\begin{array}{l}-0.018 \\
(0.031)\end{array}$ & $\begin{array}{l}0.042^{*} \\
(0.025)\end{array}$ & $\begin{array}{l}0.044^{*} \\
(0.023)\end{array}$ & $\begin{array}{l}0.052^{*} \\
(0.028)\end{array}$ & $\begin{array}{c}0.014 \\
(0.022)\end{array}$ & $\begin{array}{c}0.008 \\
(0.046)\end{array}$ \\
\hline Law & $\begin{array}{c}0.070 \\
(0.044)\end{array}$ & $\begin{array}{l}0.240^{*} \\
(0.139)\end{array}$ & $\begin{array}{c}0.151^{* *} \\
(0.069)\end{array}$ & $\begin{array}{c}0.159 * * \\
(0.065)\end{array}$ & $\begin{array}{c}0.076 \\
(0.072)\end{array}$ & $\begin{array}{c}0.133 * * \\
(0.065)\end{array}$ & $\begin{array}{c}0.488 * * \\
(0.240)\end{array}$ \\
\hline Health & $\begin{array}{c}0.108 * * * \\
(0.020)\end{array}$ & $\begin{array}{c}0.223^{* * *} \\
(0.055)\end{array}$ & $\begin{array}{c}0.256^{* * *} \\
(0.044)\end{array}$ & $\begin{array}{c}0.241^{* * *} \\
(0.041)\end{array}$ & $\begin{array}{c}0.243^{* * *} \\
(0.048)\end{array}$ & $\begin{array}{c}0.201^{* * *} \\
(0.045)\end{array}$ & $\begin{array}{c}0.410^{* * *} \\
(0.112)\end{array}$ \\
\hline Sci/Tech & $\begin{array}{c}0.044 * * * \\
(0.013)\end{array}$ & $\begin{array}{c}0.082 * * * \\
(0.031)\end{array}$ & $\begin{array}{c}0.119 * * * \\
(0.034)\end{array}$ & $\begin{array}{c}0.096 * * * \\
(0.028)\end{array}$ & $\begin{array}{c}0.083 * * \\
(0.033)\end{array}$ & $\begin{array}{c}0.076^{* * *} \\
(0.026)\end{array}$ & $\begin{array}{l}0.134 * * \\
(0.063)\end{array}$ \\
\hline Humanities & $\begin{array}{c}-0.027 \\
(0.048)\end{array}$ & $\begin{array}{l}-0.080 \\
(0.172)\end{array}$ & $\begin{array}{l}-0.007 \\
(0.134)\end{array}$ & $\begin{array}{l}-0.025 \\
(0.067)\end{array}$ & $\begin{array}{c}0.059 \\
(0.071)\end{array}$ & $\begin{array}{c}0.015 \\
(0.062)\end{array}$ & $\begin{array}{l}-0.060 \\
(0.274)\end{array}$ \\
\hline Soc. Sci. & $\begin{array}{c}0.082^{* * *} \\
(0.026)\end{array}$ & $\begin{array}{c}0.141 \\
(0.130) \\
\end{array}$ & $\begin{array}{c}0.161^{* * *} \\
(0.046)\end{array}$ & $\begin{array}{c}0.161^{* * *} \\
(0.039)\end{array}$ & $\begin{array}{c}0.182 * * * \\
(0.043)\end{array}$ & $\begin{array}{c}0.119 * * * \\
(0.039)\end{array}$ & $\begin{array}{c}0.257 \\
(0.182) \\
\end{array}$ \\
\hline $\mathrm{N}$ & 796,724 & 194,895 & 796,724 & 766,462 & 671,040 & 754,396 & 194,895 \\
\hline
\end{tabular}

Notes: Significance at 1\%***, 5\%** and 10\%*. Columns (1) and (2) reflect application-weighted means of threshold-crossing estimates from equation (1).

Columns (3) through (7) reflect application-weighted means of instrumental variable estimates of equation (4), with comparative advantage terms as specified in the column label. Results are presented for the samples of degrees defined in row labels. Homogeneous effects estimates and 1982-1989

subsample estimates impose the restriction $\phi=0$. Selectivity tier is defined by quartiles of average cutoff values across the 1982-2006 period. Standard errors computed using wild-bootstrap procedure (Cameron et al. 2008, Davidson and MacKinnon 2010). Online Appendix Sections VI and VII provide further details on estimation. 
Table 6: Earnings Effects by Field of Study and Selectivity

\begin{tabular}{|c|c|c|c|c|}
\hline & (1) & (2) & (3) & (4) \\
\hline & \multicolumn{2}{|c|}{ Less selective } & \multicolumn{2}{|c|}{ More selective } \\
\hline & Threshold-crossing & Homogeneous effects & Threshold-crossing & Homogeneous effects \\
\hline \multirow[t]{2}{*}{ Business } & -0.010 & 0.026 & 0.059 & 0.165 \\
\hline & $(0.030)$ & $(0.041)$ & $(0.046)$ & $(0.199)$ \\
\hline \multirow[t]{2}{*}{ Art/Arch. } & 0.023 & 0.056 & -0.046 & 0.001 \\
\hline & $(0.046)$ & $(0.053)$ & $(0.036)$ & $(0.059)$ \\
\hline \multirow[t]{2}{*}{ Education } & 0.022 & $0.051 * *$ & -0.022 & 0.000 \\
\hline & $(0.014)$ & $(0.022)$ & $(0.045)$ & $(0.083)$ \\
\hline \multirow[t]{2}{*}{ Law } & -0.015 & 0.011 & $0.093^{*}$ & $0.188^{* *}$ \\
\hline & $(0.055)$ & $(0.068)$ & $(0.054)$ & $(0.083)$ \\
\hline \multirow[t]{2}{*}{ Health } & $0.091 * * *$ & $0.148 * * *$ & $0.111^{* * *}$ & $0.273^{* * *}$ \\
\hline & $(0.033)$ & $(0.045)$ & $(0.022)$ & $(0.049)$ \\
\hline \multirow[t]{2}{*}{ Sci/Tech } & $0.025 *$ & $0.060 * *$ & $0.062 * * *$ & $0.175^{* * *}$ \\
\hline & $(0.014)$ & $(0.025)$ & $(0.022)$ & $(0.056)$ \\
\hline \multirow[t]{2}{*}{ Humanities } & 0.015 & 0.038 & -0.057 & -0.038 \\
\hline & $(0.049)$ & $(0.056)$ & $(0.078)$ & $(0.228)$ \\
\hline \multirow[t]{2}{*}{ Soc. Sci. } & 0.040 & $0.068^{*}$ & $0.103^{* * *}$ & $0.208^{* * *}$ \\
\hline & $(0.030)$ & $(0.038)$ & $(0.036)$ & $(0.062)$ \\
\hline $\mathrm{N}$ & \multicolumn{2}{|c|}{339,415} & \multicolumn{2}{|c|}{431,376} \\
\hline
\end{tabular}


Table 7: Quantiles of Effect Distributions

\begin{tabular}{lccccc}
\hline A. Threshold-crossing & & & & \\
& Mean & Std. Dev. & P25 & P50 & P75 \\
\cline { 2 - 5 } All & 0.045 & 0.241 & -0.074 & 0.033 & 0.163 \\
Bottom Quartile & 0.020 & 0.240 & -0.083 & 0.012 & 0.119 \\
2nd Quartile & 0.037 & 0.235 & -0.083 & 0.023 & 0.145 \\
3rd Quartile & 0.034 & 0.242 & -0.085 & 0.022 & 0.149 \\
Top Quartile & 0.091 & 0.241 & -0.032 & 0.085 & 0.242 \\
& & & & & \\
Business & 0.027 & 0.236 & -0.128 & -0.002 & 0.215 \\
Art/Arch. & -0.030 & 0.191 & -0.162 & -0.059 & 0.044 \\
Education & 0.015 & 0.211 & -0.085 & -0.002 & 0.130 \\
Law & 0.070 & 0.232 & -0.048 & 0.091 & 0.268 \\
Health & 0.108 & 0.213 & -0.031 & 0.125 & 0.246 \\
Sci/Tech & 0.044 & 0.252 & -0.057 & 0.045 & 0.135 \\
Humanities & -0.027 & 0.284 & -0.078 & 0.006 & 0.072 \\
Soc. Sci. & 0.082 & 0.231 & -0.061 & 0.023 & 0.171 \\
& & & & &
\end{tabular}

B. Model estimates

All

\begin{tabular}{ccccc} 
Mean & Std. Dev. & P25 & P50 & P75 \\
\hline 0.121 & 0.280 & -0.020 & 0.103 & 0.225
\end{tabular}

$\begin{array}{lccccc}\text { Bottom Quartile } & 0.047 & 0.258 & -0.059 & 0.051 & 0.141 \\ \text { 2nd Quartile } & 0.084 & 0.241 & -0.055 & 0.073 & 0.183 \\ \text { 3rd Quartile } & 0.113 & 0.290 & 0.002 & 0.110 & 0.209 \\ \text { Top Quartile } & 0.242 & 0.292 & 0.071 & 0.216 & 0.371\end{array}$

\begin{tabular}{llllll} 
Business & 0.101 & 0.274 & -0.024 & 0.064 & 0.209 \\
Art/Arch. & 0.014 & 0.187 & -0.106 & 0.010 & 0.082 \\
Education & 0.042 & 0.221 & -0.091 & 0.031 & 0.154 \\
Law & 0.151 & 0.227 & 0.021 & 0.189 & 0.345 \\
Health & 0.256 & 0.266 & 0.090 & 0.218 & 0.420 \\
Sci/Tech & 0.119 & 0.277 & 0.001 & 0.132 & 0.216 \\
Humanities & -0.007 & 0.375 & -0.029 & 0.030 & 0.134 \\
Soc. Sci. & 0.161 & 0.343 & -0.027 & 0.063 & 0.219 \\
\hline
\end{tabular}

Notes: Panel A describes the application-weighted distribution of threshold-crossing estimates obtained using equation (1) within the set of degrees given by row labels. Panel $B$ describes the application-weighted distribution of instrumental variables estimates of equation (4), imposing the restriction that $\phi=0$. 


\begin{tabular}{|c|c|c|c|}
\hline & $\begin{array}{l}(1) \\
\text { High- } \\
\text { SES }\end{array}$ & $\begin{array}{c}(2) \\
\text { Male }\end{array}$ & $\begin{array}{l}\text { (3) } \\
\text { Comp. Advantage: } \\
\text { Math }\end{array}$ \\
\hline \multicolumn{4}{|l|}{ Descriptive Statistics } \\
\hline Median Share $\left(s_{c p}\right)$ & $\begin{array}{c}0.418 \\
(0.219)\end{array}$ & $\begin{array}{c}0.562 \\
(0.215)\end{array}$ & $\begin{array}{c}0.321 \\
(0.186)\end{array}$ \\
\hline Median Degree Effect at Baseline $\left(\hat{\theta}_{p}\right)$ & $\begin{array}{c}0.072 \\
(0.314)\end{array}$ & $\begin{array}{c}0.098 \\
(0.265)\end{array}$ & $\begin{array}{c}0.065 \\
(0.280)\end{array}$ \\
\hline Median group-specific effect $\left(\hat{\phi}^{\prime} X_{g}\right)$ & $\begin{array}{l}-0.009 \\
(0.146)\end{array}$ & $\begin{array}{c}0.007 \\
(0.088)\end{array}$ & $\begin{array}{l}-0.006 \\
(0.168)\end{array}$ \\
\hline $\begin{array}{l}\text { Regression estimates } \\
\text { Linear }\end{array}$ & & & \\
\hline Degree Effect for Baseline ( $\left.\hat{\theta}_{p}\right)$ & $\begin{array}{l}0.183^{*} \\
(0.100)\end{array}$ & $\begin{array}{c}0.048 \\
(0.066)\end{array}$ & $\begin{array}{c}0.038 \\
(0.093)\end{array}$ \\
\hline Group-specific effect $\left(\hat{\phi}^{\prime} X_{g}\right)$ & $\begin{array}{c}0.070 \\
(0.125)\end{array}$ & $\begin{array}{l}-0.087 \\
(0.072)\end{array}$ & $\begin{array}{l}-0.071 \\
(0.150)\end{array}$ \\
\hline Binary & & & \\
\hline Degree Effect for Baseline ( $\left.\hat{\theta}_{p}\right)$ & $\begin{array}{l}0.071 * \\
(0.037)\end{array}$ & $\begin{array}{l}0.048 * \\
(0.029)\end{array}$ & $\begin{array}{l}-0.003 \\
(0.029)\end{array}$ \\
\hline Group-specific effect $\left(\hat{\phi}^{\prime} X_{g}\right)$ & $\begin{array}{c}0.026 \\
(0.048)\end{array}$ & $\begin{array}{l}-0.031 \\
(0.030)\end{array}$ & $\begin{array}{l}-0.017 \\
(0.046)\end{array}$ \\
\hline
\end{tabular}

Notes: Significance at $1 \% * * *, 5 \% * *$ and $10 \% *$. Panel A: Descriptive statistics student shares, estimated average effects for baseline-group students (i.e., effects for low-SES students in high-SES column, etc.), and estimates of $\hat{\phi}^{\prime} X_{g(c, p)}$. Weighted by marginal applicants. Panel B: Results from regressions of degree-specific average effects and indices of degree-specific comparative advantage for students with characteristics indicated in the column on the share of such students in the marginal sample, as described in equation (5). Dependent variables are given by the row labels. Linear specifications treat student share as a continuous variable, while binary specifications use an indicator variable equal to one for degrees with above-median share. Standard errors computed using wild-bootstrap procedure (Cameron et al. 2008, Davidson and MacKinnon 2010). Online Appendix Sections VI and VII provide further details on estimation. 
Table 9: Heterogeneous Effects by SES

\begin{tabular}{|c|c|c|c|c|}
\hline & (1) & (2) & (3) & (4) \\
\hline & \multicolumn{2}{|c|}{ High-SES } & \multicolumn{2}{|c|}{ Low-SES } \\
\hline Bottom Quartile & \multicolumn{2}{|c|}{$\begin{array}{c}0.045 \\
(0.048)\end{array}$} & \multicolumn{2}{|c|}{$\begin{array}{c}0.012 \\
(0.021)\end{array}$} \\
\hline 2nd Quartile & \multicolumn{2}{|c|}{0.064} & \multicolumn{2}{|c|}{$0.073 * * *$} \\
\hline 3rd Quartile & \multicolumn{2}{|c|}{$\begin{array}{c}0.115^{* *} \\
(0.052)\end{array}$} & \multicolumn{2}{|c|}{$\begin{array}{c}0.106^{* * *} \\
(0.035)\end{array}$} \\
\hline \multirow[t]{2}{*}{ Top Quartile } & \multicolumn{2}{|c|}{$\begin{array}{c}0.226 * * * \\
(0.060)\end{array}$} & \multicolumn{2}{|c|}{$\begin{array}{c}0.184^{* * *} \\
(0.053)\end{array}$} \\
\hline & Low-Sel & High-Sel & Low-Sel & High-Sel \\
\hline Business & $\begin{array}{c}0.042 \\
(0.085)\end{array}$ & $\begin{array}{c}0.307^{* *} \\
(0.121)\end{array}$ & $\begin{array}{l}-0.014 \\
(0.049)\end{array}$ & $\begin{array}{c}0.014 \\
(0.097)\end{array}$ \\
\hline Art/Arch. & $\begin{array}{l}-0.086 \\
(0.089)\end{array}$ & $\begin{array}{l}-0.036 \\
(0.078)\end{array}$ & $\begin{array}{l}-0.018 \\
(0.060)\end{array}$ & $\begin{array}{c}0.031 \\
(0.077)\end{array}$ \\
\hline Education & $\begin{array}{c}0.061 \\
(0.076)\end{array}$ & $\begin{array}{c}0.015 \\
(0.105)\end{array}$ & $\begin{array}{l}0.049 * \\
(0.026)\end{array}$ & $\begin{array}{c}0.079 \\
(0.073)\end{array}$ \\
\hline Law & $\begin{array}{l}-0.103 \\
(0.127)\end{array}$ & $\begin{array}{c}0.116 \\
(0.120)\end{array}$ & $\begin{array}{c}0.021 \\
(0.071)\end{array}$ & $\begin{array}{c}0.081 \\
(0.109)\end{array}$ \\
\hline Health & $\begin{array}{l}-0.024 \\
(0.080)\end{array}$ & $\begin{array}{c}0.261^{* * *} \\
(0.072)\end{array}$ & $\begin{array}{c}0.204^{* * *} \\
(0.055)\end{array}$ & $\begin{array}{c}0.259 * * * \\
(0.059)\end{array}$ \\
\hline Sci/Tech & $\begin{array}{c}0.050 \\
(0.057)\end{array}$ & $\begin{array}{c}0.145^{* *} \\
(0.071)\end{array}$ & $\begin{array}{c}0.030 \\
(0.028)\end{array}$ & $\begin{array}{l}0.098 * \\
(0.052)\end{array}$ \\
\hline Humanities & $\begin{array}{l}-0.097 \\
(0.128)\end{array}$ & $\begin{array}{c}0.022 \\
(0.141)\end{array}$ & $\begin{array}{c}0.016 \\
(0.055)\end{array}$ & $\begin{array}{c}0.257 \\
(0.186)\end{array}$ \\
\hline Soc. Sci. & $\begin{array}{c}0.153 \\
(0.113)\end{array}$ & $\begin{array}{c}0.248 * * * \\
(0.080)\end{array}$ & $\begin{array}{c}0.017 \\
(0.041)\end{array}$ & $\begin{array}{c}0.236 * * * \\
(0.070)\end{array}$ \\
\hline
\end{tabular}

Notes: Significance at $1 \% * * *, 5 \% * *$ and $10 \% *$. Instrumental variables estimates of equation (4) allowing for heterogeneous effects by student SES. Selectivity tier is defined by quartiles of average cutoff values across the 19822006 period. Standard errors computed using wild-bootstrap procedure (Cameron et al. 2008, Davidson and MacKinnon 2010). Online Appendix Sections VI and VII provide further details on estimation. 
Table 10: Tuition Differences Across Degree Programs

\begin{tabular}{|c|c|c|c|c|c|}
\hline & $\begin{array}{c}\text { (1) } \\
\text { Earnings Effects }\end{array}$ & $\begin{array}{c}(2) \\
\text { Tuition } \\
\text { payments }\end{array}$ & $\begin{array}{c}(3) \\
\text { Earnings } \\
\text { PDV } \\
\end{array}$ & $\begin{array}{c}\text { (4) } \\
\text { Tuition PDV }\end{array}$ & $\begin{array}{c}(5) \\
\text { Difference }\end{array}$ \\
\hline Business & 0.101 & 1.434 & 1.149 & 1.230 & -0.102 \\
\hline Art/Arch. & 0.014 & 1.423 & 0.159 & 1.251 & -1.07 \\
\hline Education & 0.042 & 0.975 & 0.478 & 0.852 & -0.374 \\
\hline Law & 0.151 & 1.684 & 1.718 & 1.463 & 0.255 \\
\hline Health & 0.256 & 1.839 & 2.912 & 1.591 & 1.321 \\
\hline Sci/Tech. & 0.119 & 1.396 & 1.354 & 1.203 & 0.151 \\
\hline Humanities & -0.007 & 1.179 & -0.080 & 1.028 & -1.108 \\
\hline Soc. Sci. & 0.161 & 1.423 & 1.832 & 1.230 & 0.602 \\
\hline $\begin{array}{l}\text { Bottom } \\
\text { Quartile }\end{array}$ & 0.047 & 0.97 & 0.535 & 0.844 & -0.309 \\
\hline 2nd Quartile & 0.084 & 1.166 & 0.956 & 1.012 & -0.056 \\
\hline 3rd Quartile & 0.113 & 1.509 & 1.286 & 1.310 & -0.024 \\
\hline Top Quartile & 0.242 & 1.915 & 2.753 & 1.646 & 1.107 \\
\hline \multicolumn{6}{|c|}{$\begin{array}{l}\text { Notes: Comparison of earnings effects and tuition by degree program characteristics. Earnings effects are } \\
\text { instrumental variables estimates of degree effects from the homogeneous effects model. They are reproduced } \\
\text { from Tables } 4 \text { and } 5 \text {. "Tuition" column reflects the sum of observed tuition payments over the six years } \\
\text { following application for accepted students in the marginal sample in the } 2007 \text { admission cohort. "Tuition } \\
\text { PDV” reflects the sum of tuition over the same years, discounted to the application year at a } 6 \% \text { interest rate. } \\
\text { "Earnings PDV" reflects the average annual earnings effect from column (1) discounted through for years } 7 \\
\text { through } 48 \text { following college application, or approximately age 65. "Difference" takes the difference between } \\
\text { columns (4) and (3). }\end{array}$} \\
\hline
\end{tabular}


FIGURE 1

Histogram of College Entrance Exam Scores

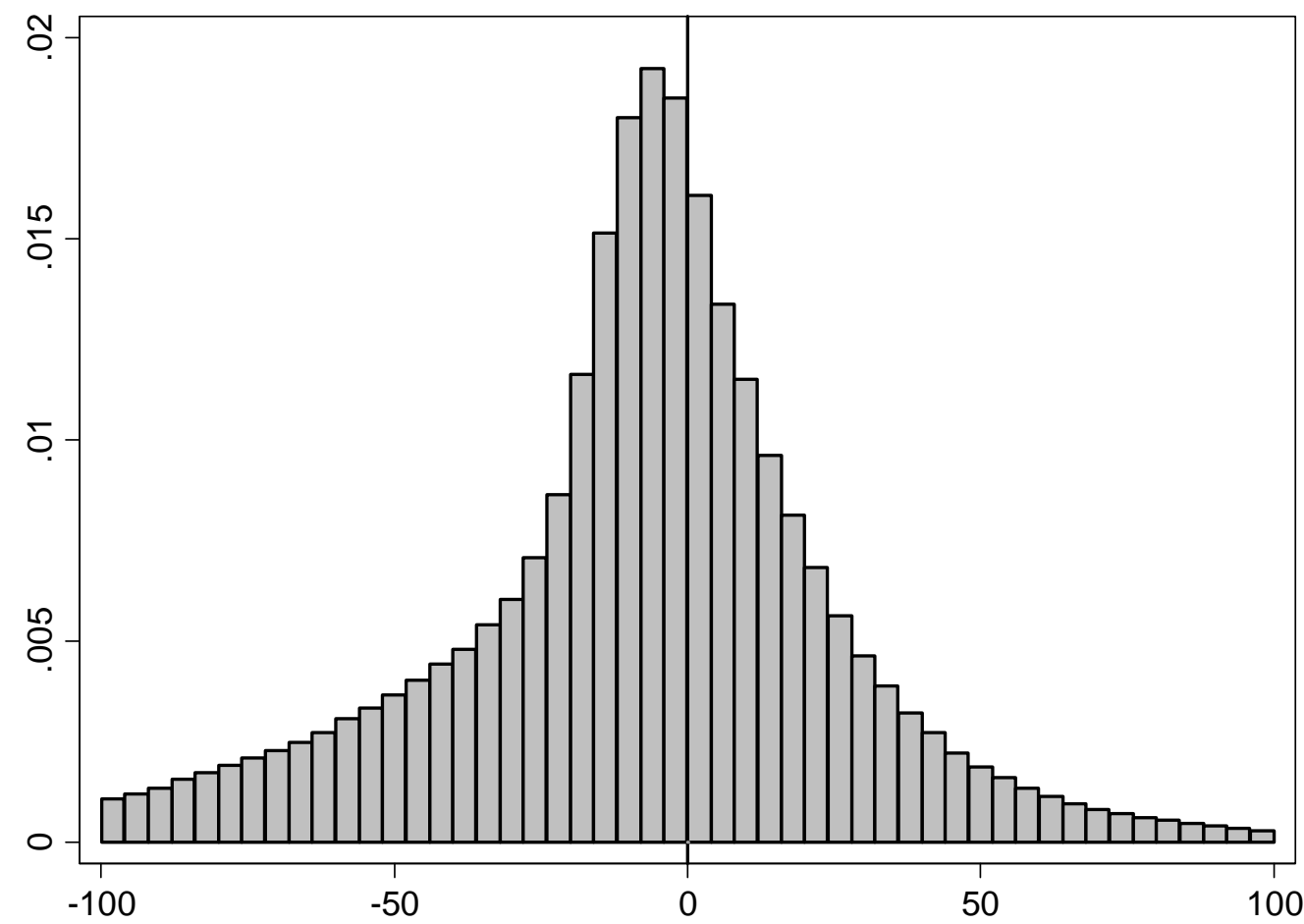

Notes: Histogram of scores relative to the admissions cutoff score within four point bins. Pooled over all applications to selective programs in the 1982-2006 cohorts. 
FIGURE 2

\section{Balance on Index}

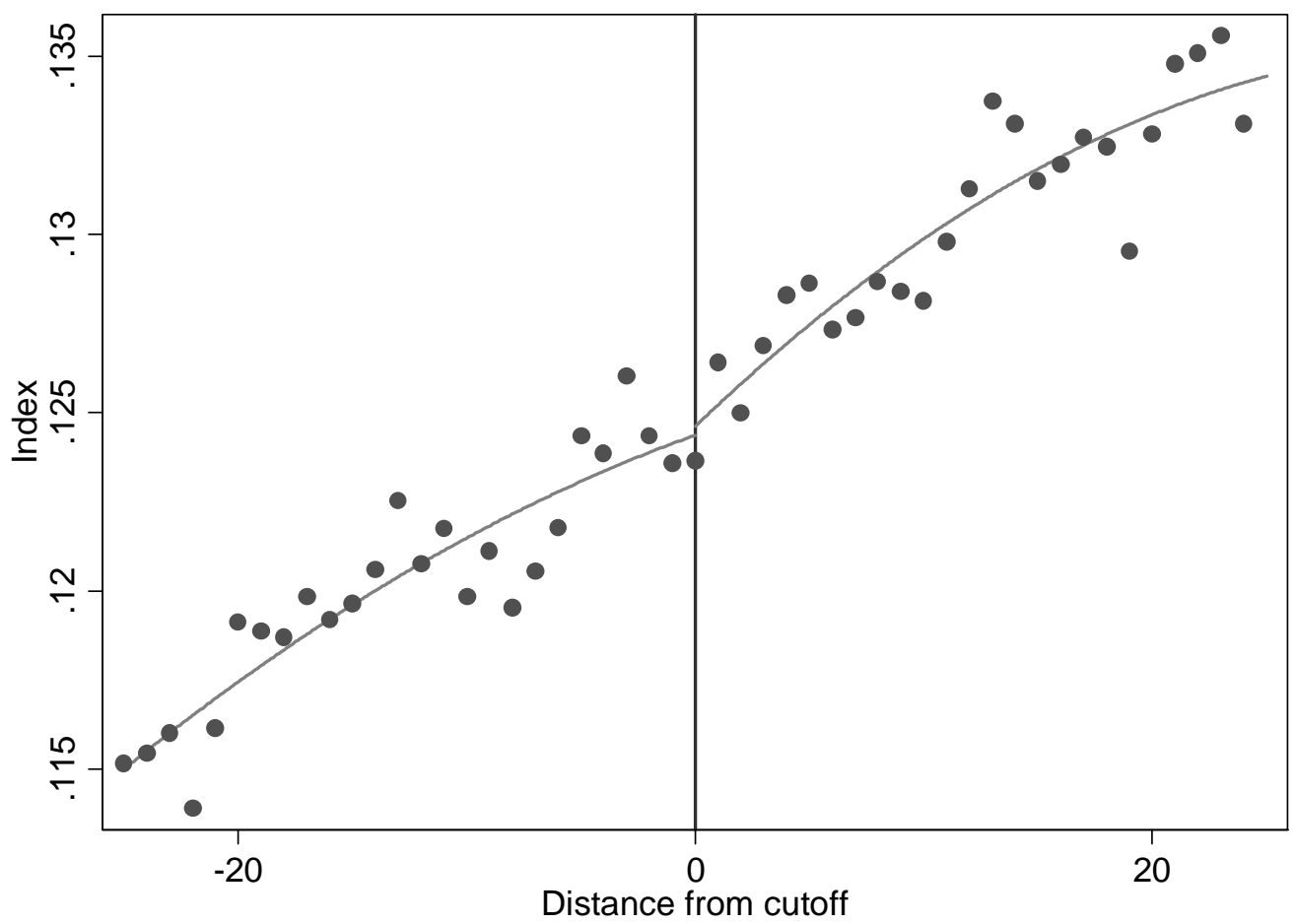

Notes: Fitted values and means within one point bins of an index of observable determinants of labor force outcomes by distance relative to the admissions cutoff. Baseline characteristics index is the portion of earnings predicted by gender and high school type in an OLS regression of labor market earnings that also controls for cohort fixed effects. Sample pools over all marginal applications in the 1998-2011 application cohorts. 
FIGURE 3

Matriculation

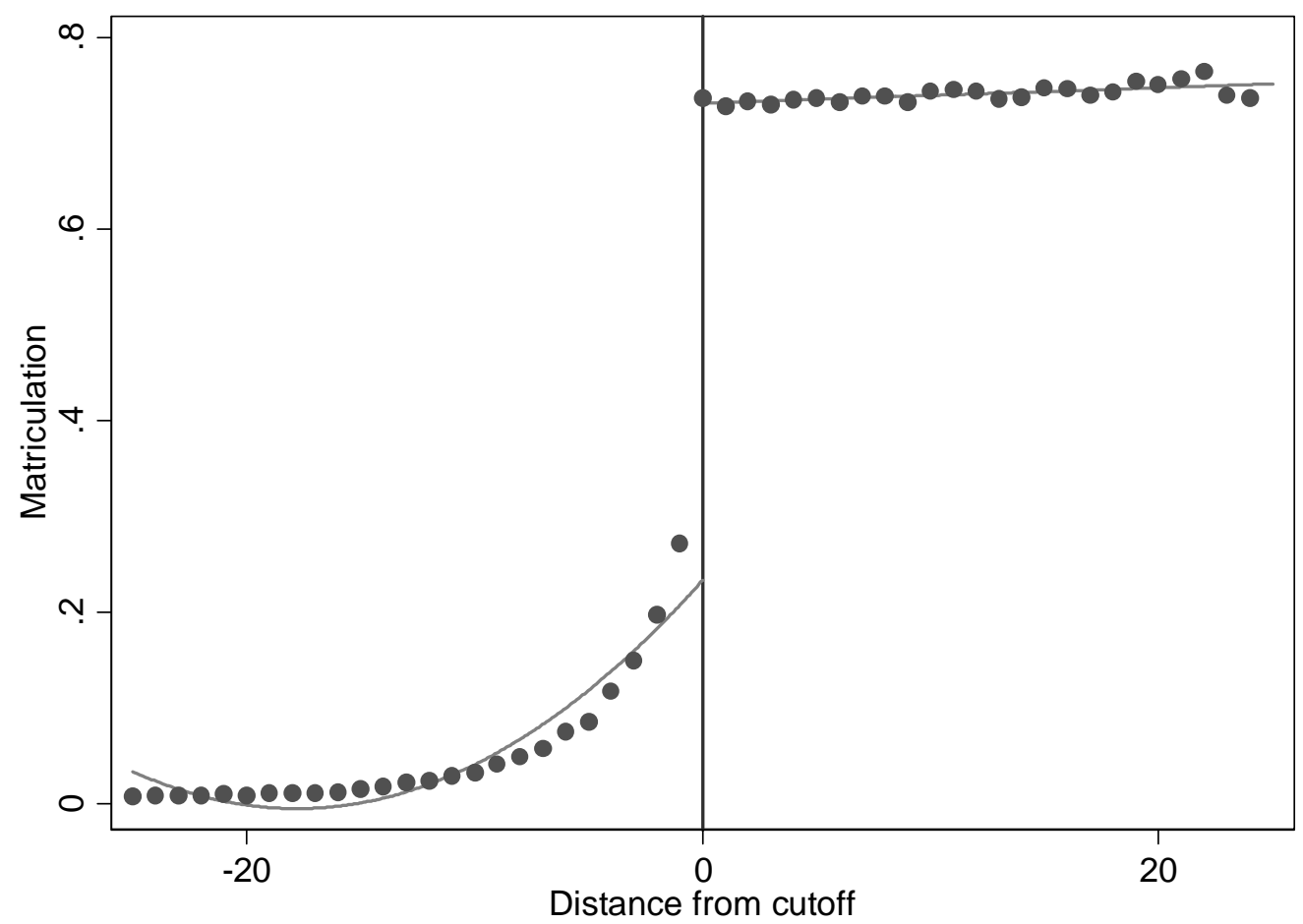

Notes: Fitted values and means within one point bins of a dummy for matriculation at the target degree program by distance relative to the admissions cutoff. Sample pools over all marginal applications in the 2000-2011 application cohorts. 


\section{FIGURE 4}

\section{Pooled Earnings Discontinuity}

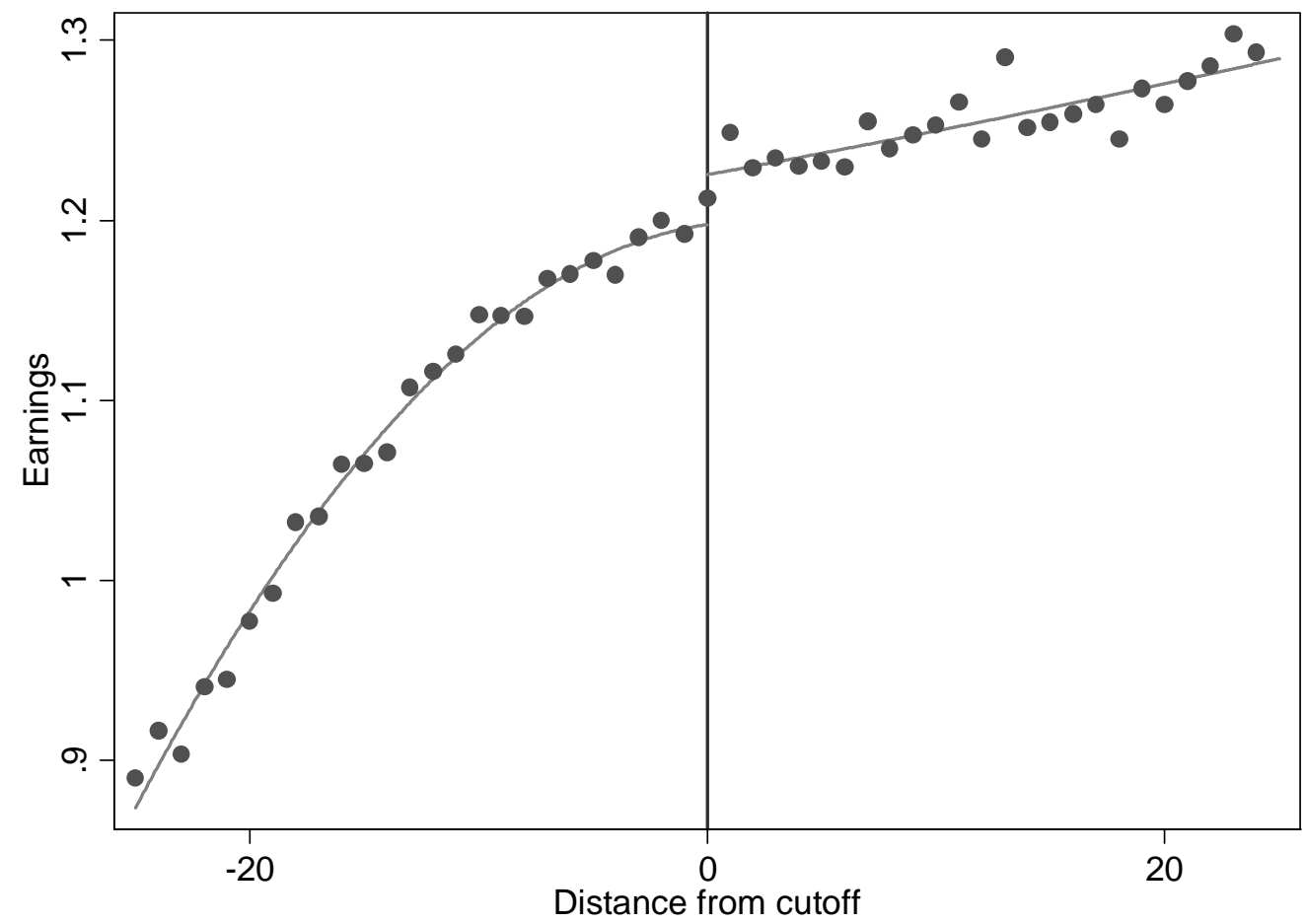

Notes: Fitted values and means within one point bins of earnings outcomes by distance relative to the threshold. Sample pools over all marginal applications in the 1982-2006 cohorts. Earnings outcomes reflect averages over annual earnings realized at least six years after the application year. 
FIGURE 5

Earnings Discontinuities by Selectivity
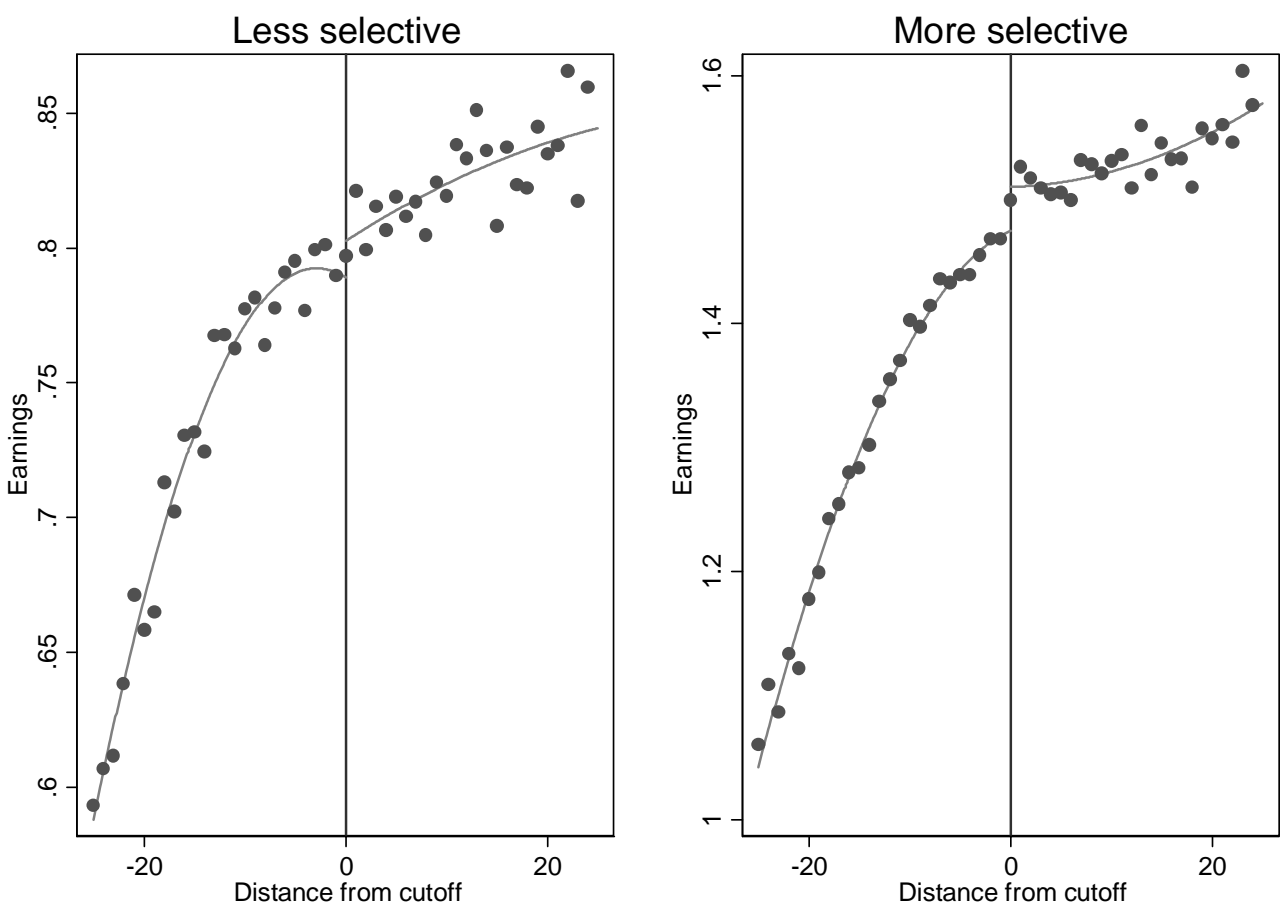

Notes: Fitted values and means within one point bins of earnings outcomes by degree selectivity and distance relative to the threshold. Sample pools over all marginal applications in the 1982-2006 cohorts. Earnings outcomes measured reflect averages over annual earnings realized between at least six years after the application year. Less-selective and more-selective are defined as degrees with below- or above-median average admission cutoff-scores over the 1982-2006 sample. 
FIGURE 6

6.A. Effects bv Characteristics

\section{Earnings Effects by Selectivity}

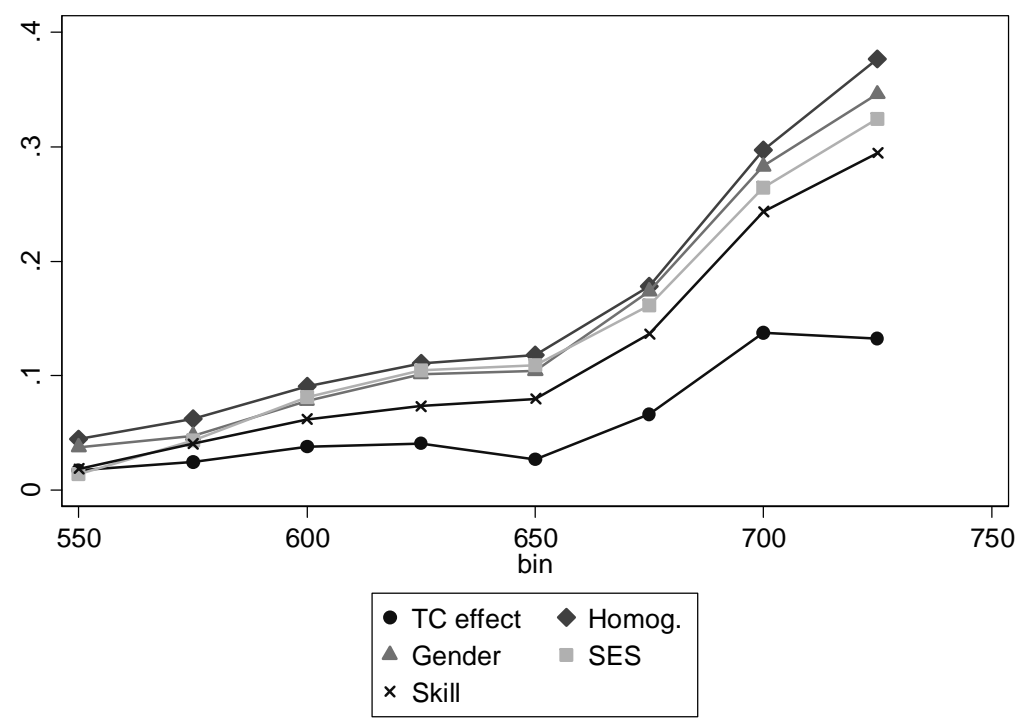

\section{B. Loan vs. non-loan takers}

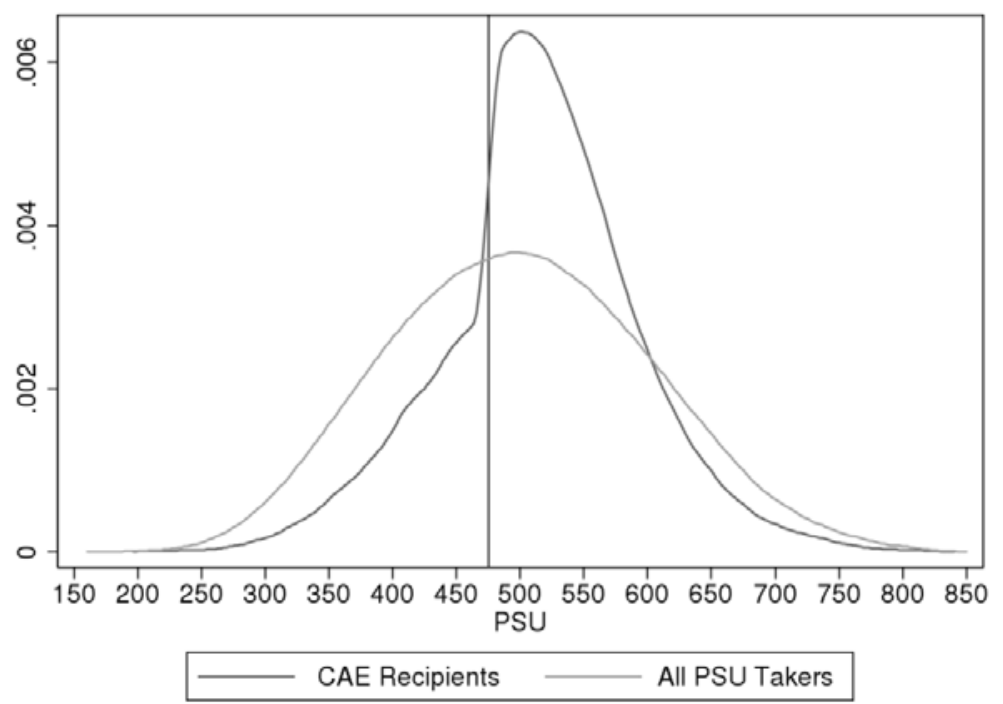

Notes: Threshold crossing effects and model estimates by degree selectivity. Graph shows application-weighted means of degree-specific estimates of equations (1) and (4) within 50 point score bins centered at each point (i.e., within a 25 point window on either side). Estimates of equation (4) include the homogeneous effects model as well as models that allow for heterogeneous effects by gender, socioeconomic status, and relative skill, as described in section 4.2. Degrees with thresholds below 525 or above 725 are added to the lowest and highest bins, respectively. 
FIGURE 7.A.

Earnings Discontinuities by Area
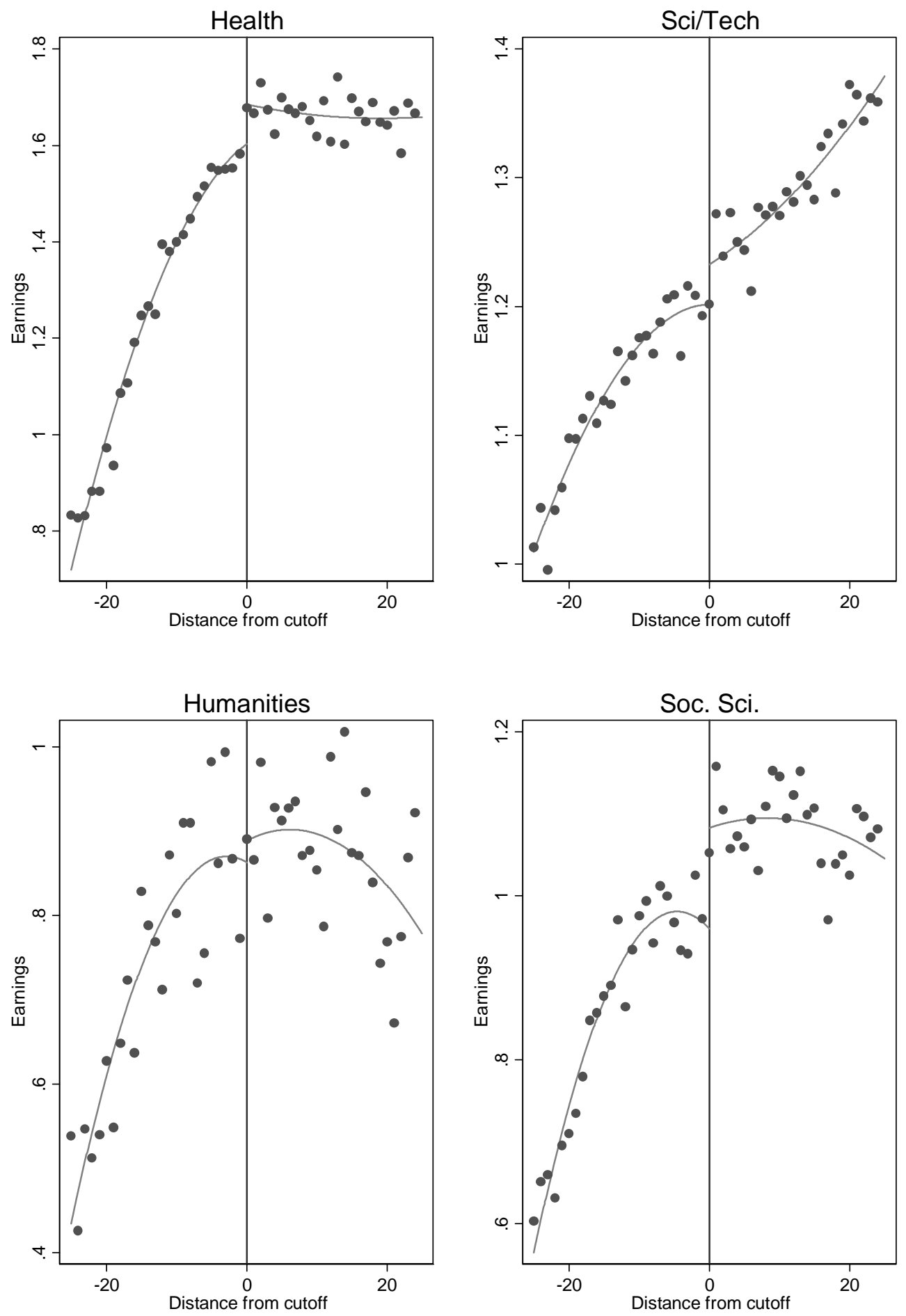
FIGURE 7.B.

Earnings Discontinuities by Area
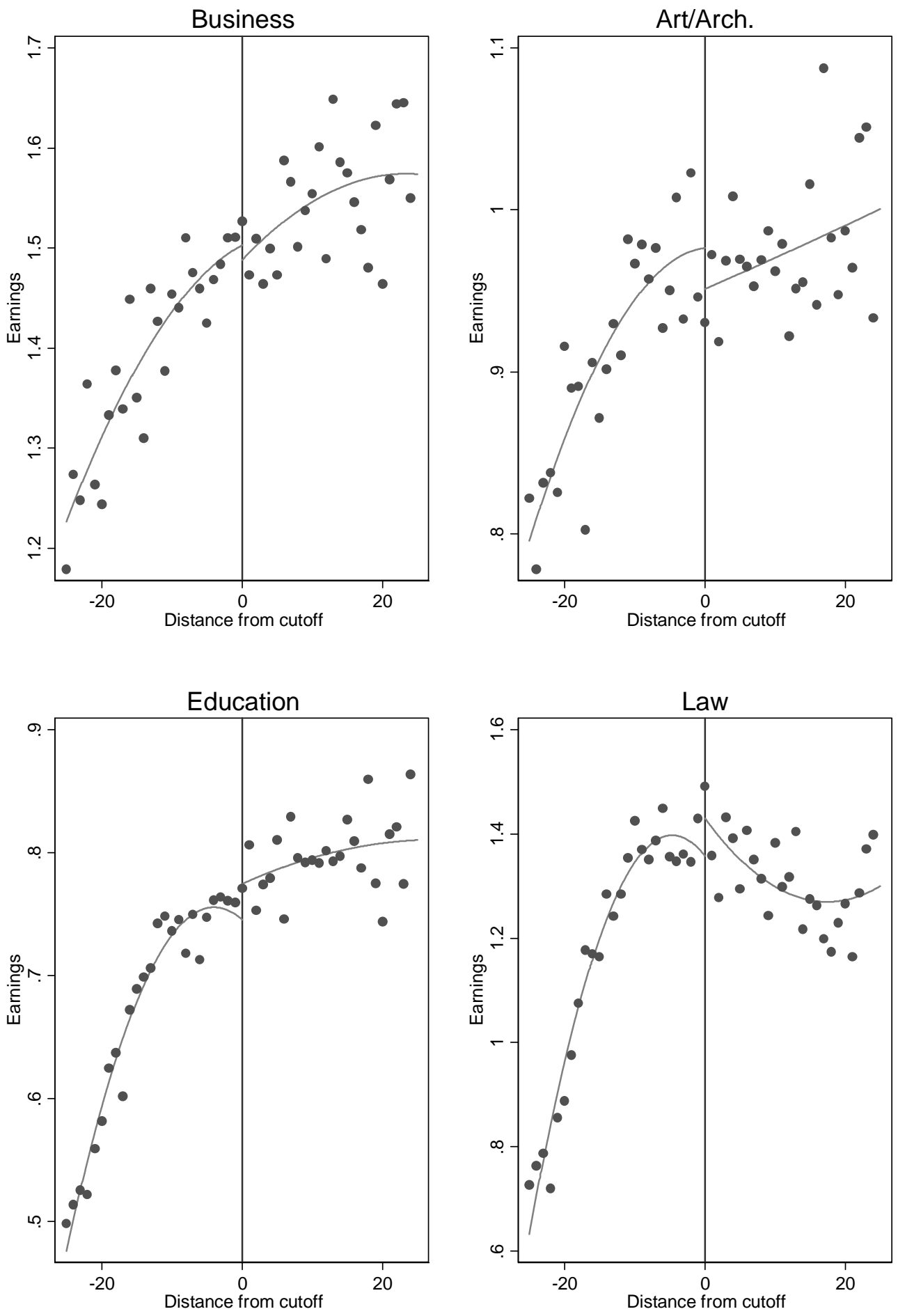
FIGURE 8

Distributions of Threshold-Crossing Effects and Model Estimates

\section{A. Threshold-Crossing Effects}
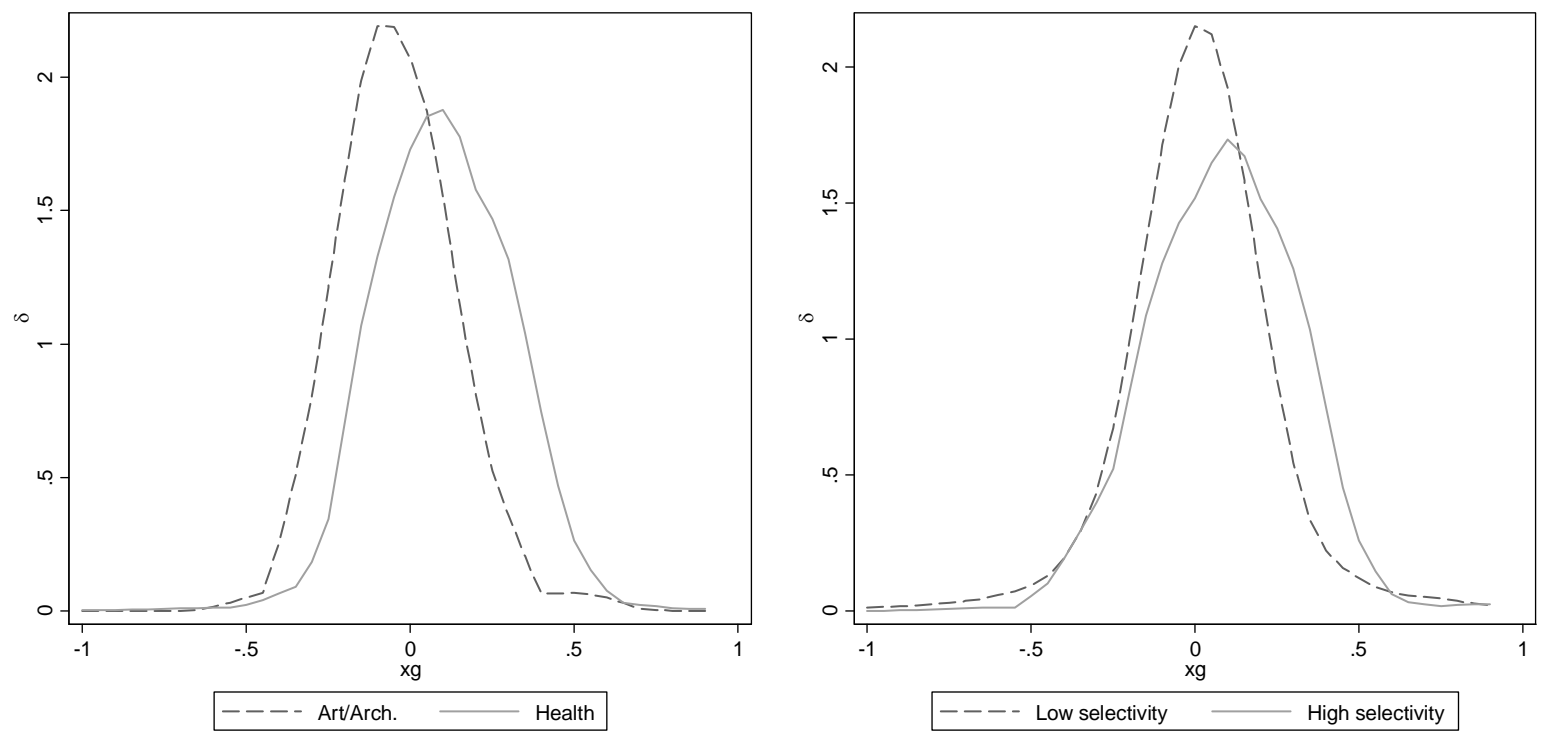

\section{B. Model Estimates}
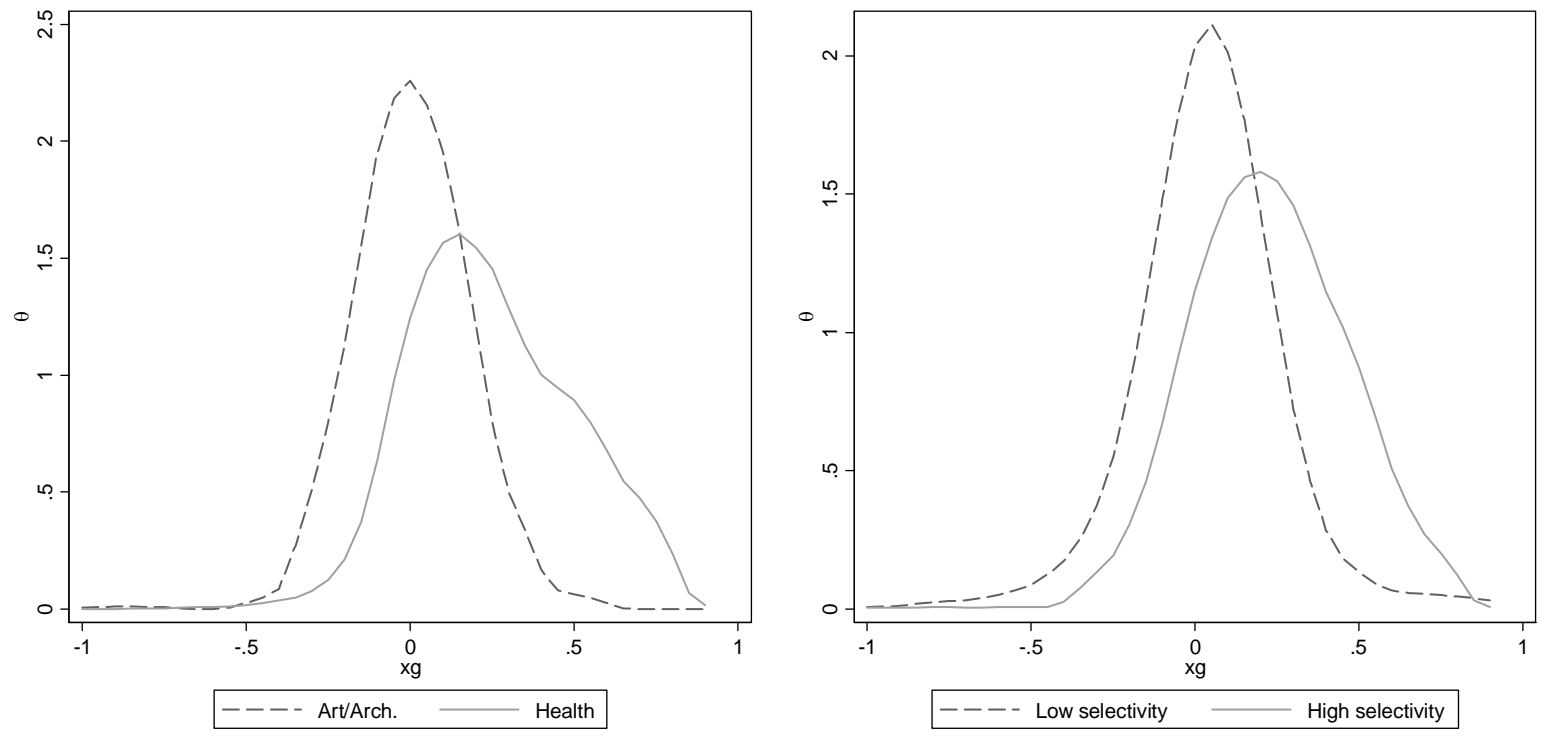

Notes: Panel A: Comparisons of the application-weighted distributions of threshold-crossing effects estimated using equation (1) for, respectively, art/architecture and health degrees, and for high- and low-selectivity degrees. Panel B: Equivalent comparisons for estimates of the homogeneous effects specification from equation (4). Epanechnikov kernel with bandwidth $\mathrm{h}=0.1$. 